Check for updates

Cite this: Mater. Chem. Front. 2020, 4, 3444

Received 6th May 2020

Accepted 11th July 2020

DOI: 10.1039/d0qm00279h

rsc.li/frontiers-materials

\title{
Multiscale engineering of functional organic polymer interfaces for neuronal stimulation and recording
}

\author{
Yingjie Wu, $\uparrow^{a}$ Qihan Zhang, $\uparrow^{a}$ He Wang ${ }^{a}$ and Mingfeng Wang (D) *bc
}

\begin{abstract}
Development of new materials and technologies for neural interfacing, stimulation and recording has attracted increasing attention. Specifically, the applications of new polymeric materials and technologies for neuron science and engineering could benefit the treatment of neural diseases and recovery of nerve injuries, as well as establishment of brain-machine interfaces that benefit patients suffering from neural diseases or injuries. In the present review, we summarize recent progress on chemistry and processing of organic polymers across a broad range of electrically insulating polymers, semiconducting polymers and conducting polymers for neural interfacing. We particularly focus on cutting-edge techniques for neuronal stimulation, including topographical and/or biochemical guidance, optical/ electrical stimulation, and techniques for recording of neuronal responses.
\end{abstract}

\section{Introduction}

Nerve regeneration involves axonal sprouting, growth, and extension, as well as reconstructing synaptic relation with target cells, and recovering nerve-guided physiological activities. One way to control the growth and differentiation of grafted neural stem cells is to use appropriate extracellular matrix materials serving as microenvironments for cell attachment and growth. ${ }^{1-6}$ Functional organic polymer interfaces have become a promising biotic/abiotic platform for regeneration and functional recovery of damaged nerve tissues. The substrate/neuron interfaces play an important role in neural repair by neurostimulation or neuromodulation through biochemical stimulation or implanted neural electrodes to restore the function of an injured central nervous system and maintain its balance. ${ }^{7-9}$ In recent years, many studies have focused on the development of organic polymers and nanostructures. The unique biocompatibility, mechanical properties, variable morphologies and biological signal-transmitting ability of these interfaces have made them indispensable implantable matrices for nerve tissue engineering. ${ }^{10,11}$ In this review, we summarize functional organic polymers and engineering techniques suitable for neural interfacing, including micro/nano-scale grooved surfaces,

\footnotetext{
${ }^{a}$ Key Laboratory of Microsystems and Microstructures Manufacturing (Ministry of Education), School of Chemistry and Chemical Engineering, Harbin Institute of Technology, Yi kuang jie 2, Harbin 150080, China ${ }^{b}$ School of Chemical and Biomedical Engineering, Nanyang Technological University, 62 Nanyang Drive, 637459, Singapore. E-mail: mfivang@ntu.edu.sg ${ }^{c}$ School of Science and Engineering, The Chinese University of Hong Kong, Shenzhen, Guangdong, P. R. China. E-mail: wangmingfeng@cuhk.edu.cn $\dagger$ These authors contributed equally to this work.
}

micro/nano fibers, surface modification, and optical/electrical stimulation. Techniques that have been used for detection of neuronal responses, which are important to establish the bidirectional feedback loop with neuronal stimulation, are also summarized.

\subsection{Research context of neuronal stimulation}

The nervous system, including the central nervous system (CNS) and peripheral nerve system (PNS), plays an important role in a human biological process, such as cognition and individual cell function. Neuronal diseases such as stroke in the brain and injuries of the spinal cord may impose tremendous consequences, such as lifelong disability, and its recovery is difficult. ${ }^{12}$ For the PNS, peripheral neuropathy can improve the regeneration of nerve axons and neuronal function by using different transplants. ${ }^{13-16}$ However, conventional autograft therapy has some serious disadvantages, such as loss of autograft function and the mismatch between autograft and recipient. And its counterpart allograft faces similar problems with disease transmission and immunogenicity. Thus, these conventional therapies are not competent to completely repair damaged nerves and function recovery due to the complexity of the nervous anatomical system.

To address these existing challenges, neural tissue engineering has rapidly emerged as a new field and has achieved lots of advances. $^{7,17-20}$ This technology applies principles of tissue engineering to neural therapy and focuses on regulating cell behavior and tissue recovery/regeneration through biomimicking implanted materials with good biocompatibility, such as extracellular matrix (ECM) analogs. ${ }^{21}$ The implanted materials should 
provide a number of chemical substances (e.g. appropriate biochemical factors and drugs) as well as physical stimulation (such as wettability, porosity, temperature, light, and electric fields) to support the adhesion and growth of neuronal cells to promote neuron differentiation, stimulate neurite growth, enhance neuronal performance and recording, and promote transmission of neuronal signals. ${ }^{22}$ Such tissue-engineering based nerve regeneration could provide hope for the treatment of Alzheimer's disease, ${ }^{23-25}$ Parkinson's disease, ${ }^{26,27}$ and a series of other degenerative brain disorders. $^{28-30}$

\subsection{Overview of previously developed materials/technologies for neuronal interfacing}

Tissue engineering scaffolds, as potential biomaterials for neural regeneration, can be fabricated from either natural or synthetic materials or biotic/abiotic composites. ${ }^{2,31-35}$ Natural biomaterials include proteins and polysaccharides. Both collagenbased scaffolds and silk fibroin nanostructured scaffolds can improve cell proliferation and differentiation performance due to their high biocompatibility and outstanding integration with native issues. ${ }^{36-40}$ Other polysaccharides and their derivatives, such as chitosan, alginate, agarose, hyaluronic acid, dextran, chitin, cellulose and so on, have also exhibited excellent performance in neural regeneration. ${ }^{41-51}$ On the other hand, numerous synthetic materials and engineering strategies have been developed for the repair of nerve lesions in the past decade. To stimulate or record neurological functions, the majority of the neural scaffolds are composed of stable and corrosion-resistant metals (e.g. gold, platinum, iridium, platinumiridium alloy, titanium, and stainless steel), ${ }^{52-55}$ inorganic semiconductors (e.g. silicon, germanium, gallium arsenide), ${ }^{5-61}$ or organic polymeric materials (e.g. conducting polymers), or carbon-based materials (e.g. carbon nanotubes, graphene hydrogels containing protein-based materials), or tissue-engineered constructs containing cells. ${ }^{62-67}$ These synthetic materials have been popular choices for developing next-generation neural interfaces. For instance, some metal electrodes such as Utahand Michigan-type series have been used for clinical stimulation and recording of neurons. Nevertheless, a major limitation of these metal electrodes is that they are often invasive and that complications such as inflammatory responses could occur at the metal/tissue interfaces, mainly due to the mechanical mismatch.

Carbon nanotubes (CNTs) and carbon nanofibers (CNFs) as synthetic materials have attracted lots of interest in neural tissue engineering. ${ }^{68-70}$ They can contact cell membranes tightly to improve the differentiation of stem cells into favorable cell types. CNTs and CNFs can also direct neuronal growth and neurite extension due to their excellent mechanical and electrical properties, as well as special surface chemical properties. In addition, graphene has emerged as another type of twodimensional (2D) carbon-based electrically conducting material for neural regeneration. ${ }^{71}$ However, there are still challenges in the clinical applications of CNTs, CNFs and graphenes in terms of their long-term degradability and mechanical mismatch with neuronal cells and tissues.
Until now, lots of fabrication techniques have been developed to create biomimetic scaffolds, including micro/nanomachining, ${ }^{72,73}$ photolithography, ${ }^{7475}$ colloidal lithography, ${ }^{76}$ chemical etching, ${ }^{77}$ electrospinning, ${ }^{78} 3 \mathrm{D}$ printing, ${ }^{79-82}$ and self-assembly. ${ }^{83}$ Various interfaces of scaffolds can be precisely modified using these technologies. Synthetic biomaterials including 3D scaffolds and nerve conduits have shown significant promise in strategies for repair and regeneration in the peripheral and central nervous systems. $^{84}$

\subsection{Why polymers for neuronal stimulation?}

Among various functional materials, organic polymers have been widely used in nerve repair and regeneration. The rational design of organic polymer materials for neural tissue engineering offers several distinct advantages over other materials, such as mechanical flexibility and synthetic variety that enables specific tailoring of mechanical, chemical, optical, electrical, and biological properties. ${ }^{85}$ Various interfaces of scaffolds with precise material geometries, localization of biomolecular cues, and mechanical properties could be controlled and defined. For instance, to further reduce the mechanical mismatch between the polymeric substrates and nerve tissues, the integration of functional polymers and flexible polymers (e.g. parylene $\mathrm{C},{ }^{86}$ polydimethylsiloxane (PDMS), ${ }^{87}$ polyimide (PI), ${ }^{88}$ and silk fibroin ${ }^{89}$ ) is a main solution to achieve enhanced mechanical flexibility for fabricating flexible neural electrodes of different shapes and sizes. For conducting polymers as neural scaffolds, there are various approaches to achieve tunable conductivity, such as secondary doping, ${ }^{90}$ thermal treatment, ${ }^{91}$ and addition of organic solvents ${ }^{92}$ or surfactants. ${ }^{93}$ These advances in both polymer science and engineering have enabled electrical and/or optical stimulation, as well as biochemical cues to improve the function of polymers as scaffolds for neural interfacing, stimulation and recording (Fig. 1).

Polymers as a large family can be divided into three primary groups, insulating polymers, semiconducting polymers and conducting polymers, according to their distinct electrical conductivities. A variety of insulating polymers have shown good biocompatibility, easily tailored topography, and mechanical properties in neural interfacing and engineering. In contrast to insulating polymers, the scope of the semiconducting polymers that have been used for neural interfacing remains limited (Fig. 5). A few semiconducting polymers have been used for photothermal and/or photoconductive stimulation of neurons with good spatiotemporal control. In addition, most of these reported semiconducting polymers are intrinsically hydrophobic, and thus extra interfacial modification is needed to improve the biocompatibility. Conducting polymers are attractive for the field of neuroscience due to their low electrochemical impedance, biocompatibility, and tissue-friendly properties. The conducting polymers reported so far are mainly limited to polyanilines, polythiophenes, polypyrroles, and their derivatives. Both semiconducting polymers and conducting polymers also have unique properties that arise from their nanoscale sizes, such as their large surface area, high electrical conductivity, electrochemical stability, and potential quantum confinement effects, which enables their 


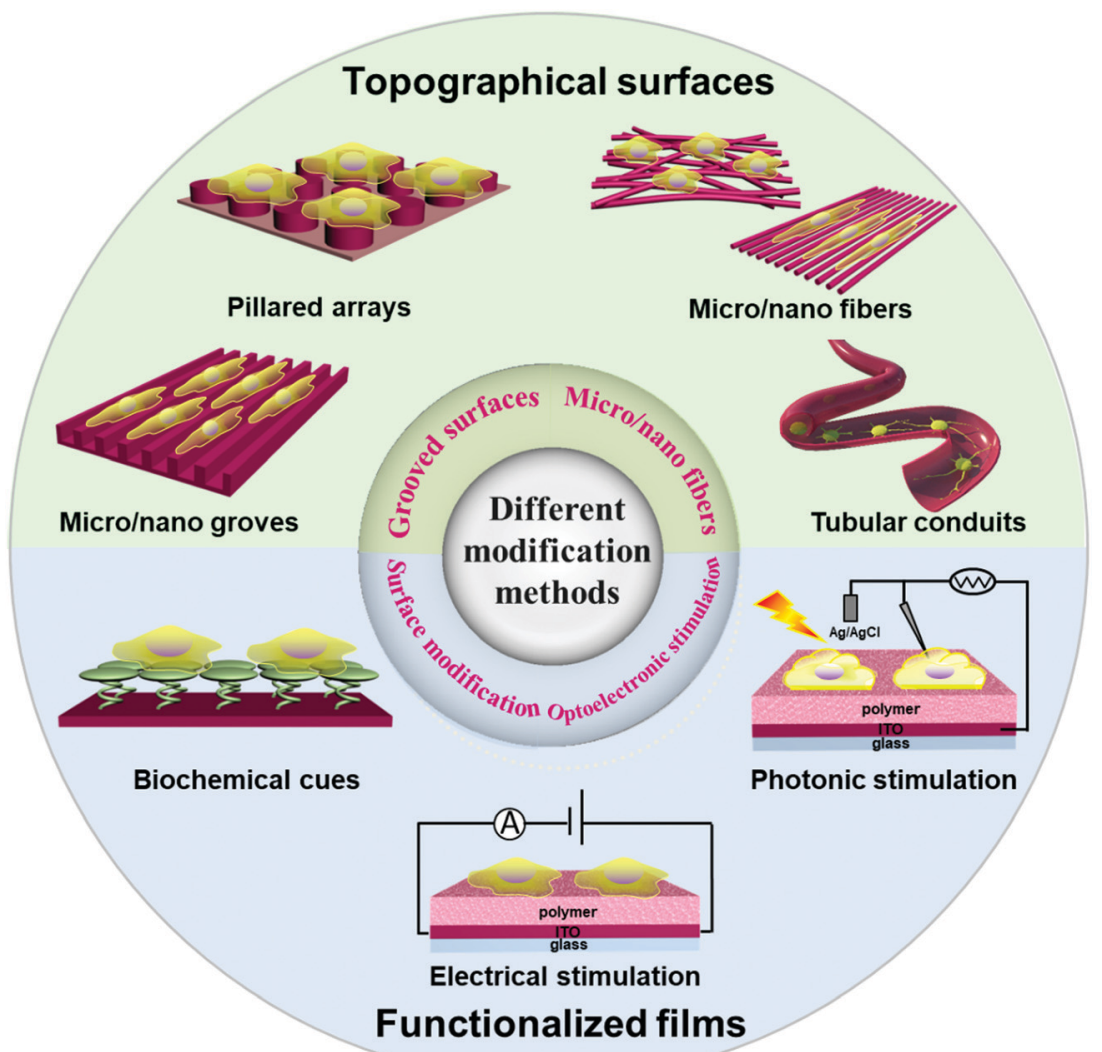

Fig. 1 Schematic illustration of polymer/neuron interfacial engineering for topographical and biochemical guidance of neural differentiation/growth, and functionalized polymer films (e.g. electrically conducting or semiconducting polymers) for spatiotemporal control of neuronal stimulation.

applications in biomedical fields including drug delivery systems, medical devices, and tissue engineering. ${ }^{94,95}$

In the following sections, we describe recent advances of these three types of polymers for neural interfacing and stimulation, in the order of insulating polymers, semiconducting polymers, and conducting polymers.

\section{Polymers for neuronal interfacing and stimulation}

\subsection{Insulating polymers for topographical and/or biochemical guidance of neurons}

This section focuses on electrically insulating polymers for neuronal interfacing and stimulation. Biocompatible insulating polymers as implants are able to establish long-term intimate interaction with host neurons. Instead of giving a comprehensive review of all the polymers that have been used for neural interfacing, here we highlight several representative studies to illustrate the effects of scaffold morphology, biochemical cues and surface wettability of scaffolds on the repair and regeneration of neuronal cells.

2.1.1 Assessment of neuronal response to topographical guidance. In the past decade, various studies were reported on the fabrication of different insulating polymer substrates with topographical surface patterns to induce cellular regeneration.
Many studies confirmed the effects of extracellular scaffolding substrates with micro/nano grooved topographies, including roughness, patterned film, and distribution of pores on the surface, which can influence not only the cell attachment but also the cell morphology, viability, differentiation and proliferation rate, orientation of growth and biological activity. ${ }^{100-102}$ Alignment as a metric of the engineering surface is important to guide neuronal directed growth. ${ }^{7,103,104}$ Neurites have been quantified in many ways to show the assessment of the neuronal response to topography, including somal or nuclear orientation for alignment, ${ }^{105}$ circular statistical methods for angular data of nuclei or neurites, ${ }^{106}$ a Fourier-transform method for analysis of the overall alignment effect ${ }^{107}$ and so on. These methods of assessing cellular and neurite outgrowth provide a quantitative manner for showing how neurons respond to topography. ${ }^{7}$ Many studies discussed in this section evaluate how the topography of insulating polymer substrates affects the alignment of neurons or the differentiation and extension of neurites in a desired orientation.

Electrospinning is a particularly powerful technique to produce oriented fibrous substrates with desired sizes and dimensions. ${ }^{108-111}$ For instance, Mahairaki et al. prepared polyL-ornithine/laminin-coated polycaprolactone fiber matrices of different diameter (nanofibers and microfibers) and orientation (aligned and random) (Fig. 2a and b) by electrospinning and functionalizing fiber matrices with ECM molecules to create an 

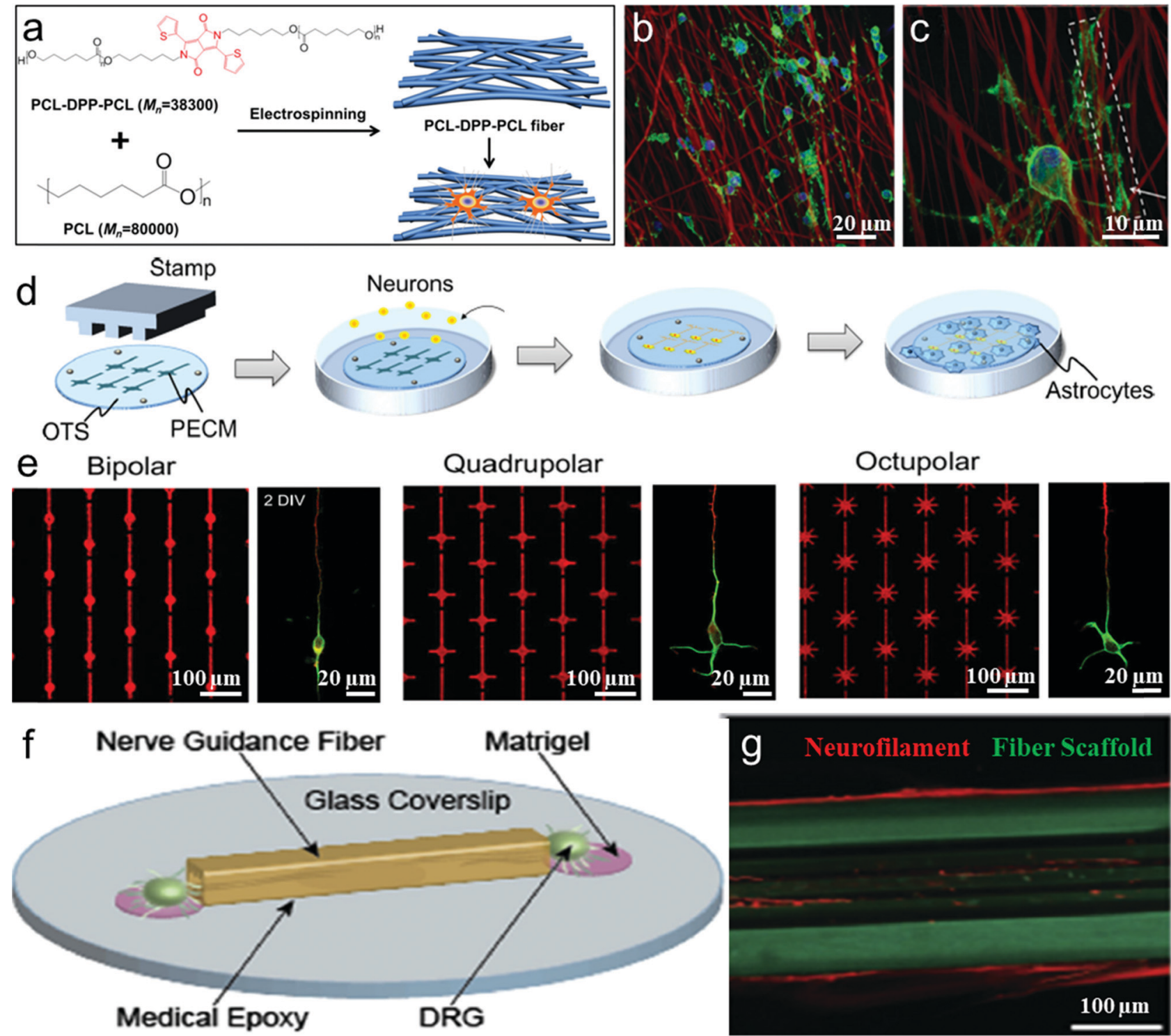

Fig. 2 (a) Schematic illustration of PCL-DPP-PCL fibers fabrication and interaction with Oligodendrocyte precursor cell (OPC). (b and c) OPC cell and PCL-DPP-PCL fiber interaction on day 3 and day $7 .{ }^{97}$ (d) Schematic illustration of the fabrication of the micropatterned substrates. (e) Fluorescence micrographs of the protein pattern, visualized by adding a fluorescent dye (SR101) to the protein solution. Fluorescence micrographs of 2 DIV neurons on the three patterns stained with an axonal marker (tau-1; red) and a somatodendritic marker (MAP2; green). ${ }^{96}$ (f) Schematic of a DRG seeded fibercoverslip assembly. (g) Neurite outgrowth is observed both within and along the surface of the fiber scaffolds. ${ }^{97}$

environment biocompatible for regulating the neuronal growth and differentiation. On the basis of their ability to sense the topography of the tissue-specific microenvironment, neural precursors (NPs) derived from human embryonic stem cells showed polarized cell morphology and the best viability with processes extending along the axis of aligned fibrous matrices. In contrast, NPs on plain tissue culture surfaces or random fiber substrates form nonpolarized neurite networks and perform a polygonal shape and grow without particular directionality (Fig. 2c and d). This demonstrates that improved fibrillar matrices of polycaprolactone have advantages in neuronal differentiation by changing migration, adhesion, proliferation, and differentiation of nerve cells. ${ }^{96}$ Meanwhile, Corey et al. have proved that neurites on highly aligned fiber bundles could change direction and grow parallel to the fiber with $16-20 \%$ increase of the neurite length. ${ }^{112}$ The aligned hydrogels fabricated by microfluidic techniques can induce neuronal axons and growth along the direction of the aligned gels. ${ }^{113}$ Wang et al. fabricated aligned nanofiber yarn/ hydrogel core-shell scaffolds for guiding 3D myoblast alignment, elongation and differentiation. ${ }^{114}$ Thus various aligned insulating polymer scaffolds are suitable for neuronal alignment, elongation, and differentiation.

In tissue engineering, long-term imaging and monitoring the cell-substrate interactions requires visualization and tracking of both cells and the substrate. Compared to various cellular tracking compounds, the fluorophores used for labeling scaffolds are still limited to fluorescein isothiocyanate (FITC) or rhodamine, which are often tagged to the end groups of polymers that form 
the extracellular matrix or scaffold. Unfortunately, in these methods, dyes that are tagged to the matrices often suffer from fast photobleaching because of their intrinsic nature of poor photostability. Their easy exposure to the environment $\left(\mathrm{O}_{2}\right.$, water, etc.) limits their applications in long-term tracking of cell-substrate interactions. To address these issues, Wang's group and Chew's group have collaborated in the design and synthesis of a series of highly fluorescent and photostable electro-spun polymeric nanofibers that serve as scaffolds for cell interfacing. ${ }^{97}$ PCL-DPP-PCL, which was synthesized by covalently linking di(thiophene-2-yl)-diketopyrrolopyrrole (DPP) as a highly fluorescent chromophore into the middle of polycaprolactone (PCL) chains, was physically blended into the electrospun fibers of commercial PCL homopolymers and significantly improved the fluorescence brightness and photostability (Fig. 2a). After 15 days of differentiation, confocal laser scanning fluorescence images show that the extension of oligodendrocyte precursor cells (OPCs) clearly wrapped around the PCL-DPP-PCL fibers (as shown by the box and arrow in Fig. $2 \mathrm{~b}$ and $\mathrm{c}$ ), followed by the formation of myelin membrane which enclosed the fluorescent PCL-DPP-PCL fibers. Such highly fluorescent scaffolds of PCL fibers with robust photostability are important to reveal the mechanisms of the topography-guided neuron/substrate interaction at the interfaces.

Furthermore, there have been several other approaches aiming to control cellular alignment during nerve regeneration, such as hydrogels, ${ }^{115-118}$ copolymer brushes, ${ }^{119}$ fibers, ${ }^{120}$ channels, ${ }^{121}$ groove/ridge patterned films ${ }^{122-127}$ and oriented protein deposition. ${ }^{116}$ Degradable hydrogels as high-watercontent biomimetic materials can be processed into different micropatterns to guide the shape and growth direction of cell regeneration and the directional conduction of nerve signals. Hydrogel surfaces can be patterned with multiple proteins to direct cell growth and attachment. ${ }^{116,128}$ Yamamoto et al. reported a study on unidirectional signal propagation in primary neurons micropatterned at a single-cell resolution by a microcontact printing $(\mu \mathrm{CP})$ method to pattern a mixture of poly-lysine/extracellular matrix gel on an octadecylsilane-coated coverslip (Fig. 2d and e). Neurons were polarized in the intended orientation of the above three pattern geometries, and thus can be controlled to direct signal propagation. ${ }^{98,129}$

Poly(PEGMA-ran-MAETAC) random copolymer brushes composed of poly(ethylene glycol) methacrylate (PEGMA) and 2-methacryloxyethyl trimethylammonium chloride (MAETAC) through surface-initiated atom transfer radical polymerization (SI-ATRP) reactions prepared by Zhou et al. could support multiple dendrites and long axons of hippocampal neurons. ${ }^{119}$ For the neuronal outgrowth on round and trilobal fibers, Chwalek et al. have proved that neurons growing on PLA regular round fibers exhibit improved outgrowth as compared to trilobal fibers. ${ }^{120}$ Hinüber et al. developed a hierarchically structured nerve guidance conduit (NCG) by slowly resorbing poly(3-hydroxybutyric acid) (P3HB) and then it successfully supported neuron survival and neurite outgrowth. ${ }^{121} \mathrm{Wu}$ et al. developed a core-shell 3D-hollow microfiber by electrospinning and proved that these hollow microfibers as controllable scaffolds could not only guide cell adherence and direction growth but also finally form controllable neuronal networks. ${ }^{130}$ In addition, Shahriari et al. developed a new technique to produce microchannels with tunable cross sections and porosity by combining fiber drawing and salt leaching to enhance neural regeneration and nerve repair. ${ }^{131}$

In addition, axon growth can be promoted on different micropatterned groove/ridge biomaterial scaffolds such as typical nano-/ micro-grooves, ${ }^{122,126,127,132}$ rectangular gradient patterned grooves with different scales, ${ }^{125}$ biodegradable materials with round contact guidance curves, ${ }^{123}$ and sinusoidal grooves. ${ }^{124}$ Anikeeva and coworkers produced a wide spectrum of polymer-based nerve guidance channels employing thermal drawing process (TDP) and analyzed the effects of channel size, geometry, and surface topography for potentially promoting nerve regeneration (Fig. 2f). These flexible, biocompatible fibrous polymer scaffolds with a variety of geometries and dimensions led to accelerated Schwann cell migration and neurite growth and alignment (Fig. 2g). ${ }^{99}$ Thus microenvironmental cues, such as stiffness, geometry, roughness, and ligand density of the scaffold can not only affect neuronal growth and elongation of neurites, but also guide synapse formation to control the direction of signal propagation. These polymer scaffolds are promising in cell-interfacing biomedical applications.

\subsubsection{Effect of multiple biomolecules on neuronal outgrowth.} In the research of interface engineering for nerve regeneration, the substrate/neuron interface can be modified with specific biochemical irritants, such as proteins and chemical cues, to improve their biocompatibility and facilitate neural cell attachment. ${ }^{134-137}$ The biochemical cues could be combined with topographical cues to create a synergistic condition for direction of neural cell behavior. The chemical cue provides chemical attraction or repellence to control neuron distribution and outgrowth, while the topographic cue provides a specific interface for neuronal adhesion. ${ }^{138,139}$

Studies of neural tissue regeneration during the past few decades have been facing the challenge of controlling neuronal differentiation into specific nerve cells. Nerve growth factor (NGF) has been widely employed for chemically immobilizing on the surface to facilitate cell-adhesion and guide the neuron polarity. ${ }^{134,140-142}$ As shown in the previous section, aligned nanofibers have the ability to significantly facilitate the differentiation of MSCs into specific cell types. Aligned NGFconjugated nanofibrous meshes have been shown to promote the neuronal outgrowth and specific differentiation. ${ }^{143,144}$ Similarly, Horne et al. modified brain-derived neurotrophic factor (BDNF) onto 3D electrospun poly( $\varepsilon$-caprolactone) (PCL) nanofiber scaffolds by fiber alignment and aminolysation and proved that these functional polymer nanofibers could enhance proliferation of stem cells and direct the cells to differentiate into specific neuronal and oligodendrocytes. ${ }^{145}$ Furthermore, Crompton et al. immobilized poly-D-lysine (PDL) onto chitosan by azidoaniline photocoupling to improve cell adhesion and neurite outgrowth. ${ }^{146}$ Koh et al. blended laminin with poly(L-lactic acid) (PLLA) solution for the electrospinning procedure. Such combined chemical and topographical cues of laminincoupled nanofibers enhance PC12 cell viability and adhesion. ${ }^{147}$ 
Moreover, pendant acetylcholine analog is a neurotransmitter for the enhancement of neuron adhesion and outgrowth. It can promote cell viability and neurite growth in a concentrationdependent manner. ${ }^{148}$ Xing et al. synthesized a biodegradable poly(ester-carbonate) with a pendant acetylcholine analog on which the cells exhibited the longest neurite length and the highest percentage of neurites. ${ }^{149}$ Long-term culture of neuron cells is required in order to develop a platform capable of sustaining neural activity over months and overcome challenging problems such as neuron-based biosensors. Yu et al. used initiated chemical vapor deposition (iCVD) and synthesized a polymeric bilayer (PGD) composed of poly(glycidyl methacrylate) (PGMA) and poly(2-(dimenthylamino)ethyl methacrylate) (PDMAEMA) which would perform a function like an acetylcholine quaternary ammonium. ${ }^{133}$ The epoxide in PGMA would interact with part of the tertiary amine moiety in the PDMAEMA layer upon iCVD, while PGMA with epoxy was deposited on a culture plate or cover glass (Fig. 3a and b). Neurons on PGD3coated (controlling the PDMAEMA composition by depositing for $6 \mathrm{~min}$ ) glass substrates, compared to those on PLL-coated glass, showed more dendrites and axonal projection as well as a higher level of MAP2 (a somatodendritic marker) expression. The dendrites of each neuron can extend around, forming evenly distributed neural networks (Fig. 3c-f).

2.1.3 Effect of surface properties on neuronal outgrowth. Besides the topography and biochemical cues, physicochemical properties such as wettability of the material/neuron interface also have notable effects on cell attachment and proliferation. ${ }^{151-157}$ Specifically, surface wettability was studied to improve nerve regeneration in repairing damaged cells and implanting scaffold grafts. In addition, cell growth or protein fouling on gliding tissue interfaces or the scaffold surface may lead to undesirable outcomes. Stevens and coworkers produced a bifunctional scaffold

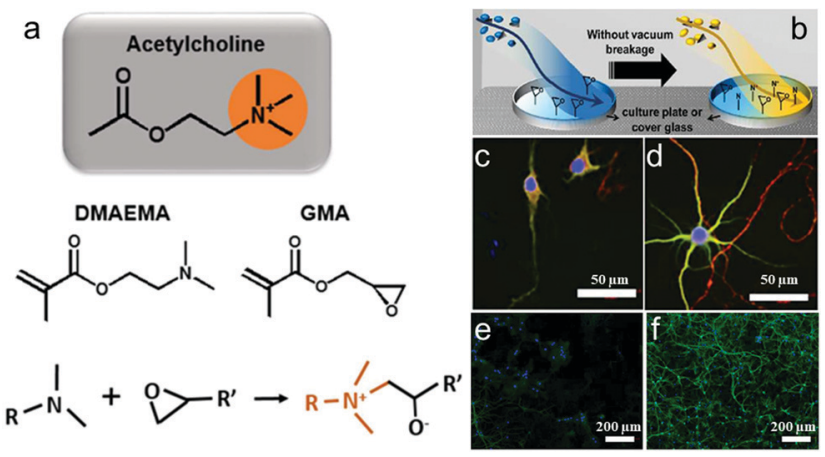

Fig. 3 Polymerization concept of a surface using initiated chemical vapor deposition (iCVD). (a) Chemical structure of acetylcholine, DMAEMA, and GMA and the conjugation reaction between the tertiary amine group in DMAEMA and epoxy group in GMA. (b) Fabricating the polymer-coated surface through sequential introduction of GMA and DMAEMA in the iCVD chamber. ( $c$ and d) Confocal microscopy images of neural growth accelerations in vitro for 8 days. Neurons immunostained for MAP2 (green) and Tau (red) and costained with the nuclear dye DRAQ5 (blue). (e and f) Immunocytochemical images of neural network morphologies distinguished after 80 days. Cells were immunostained for MAP2 (green) and costained with the nuclear dye DAPI (blue). Neurons grown on PLL (left) and PGD3 (right) surfaces. ${ }^{133}$
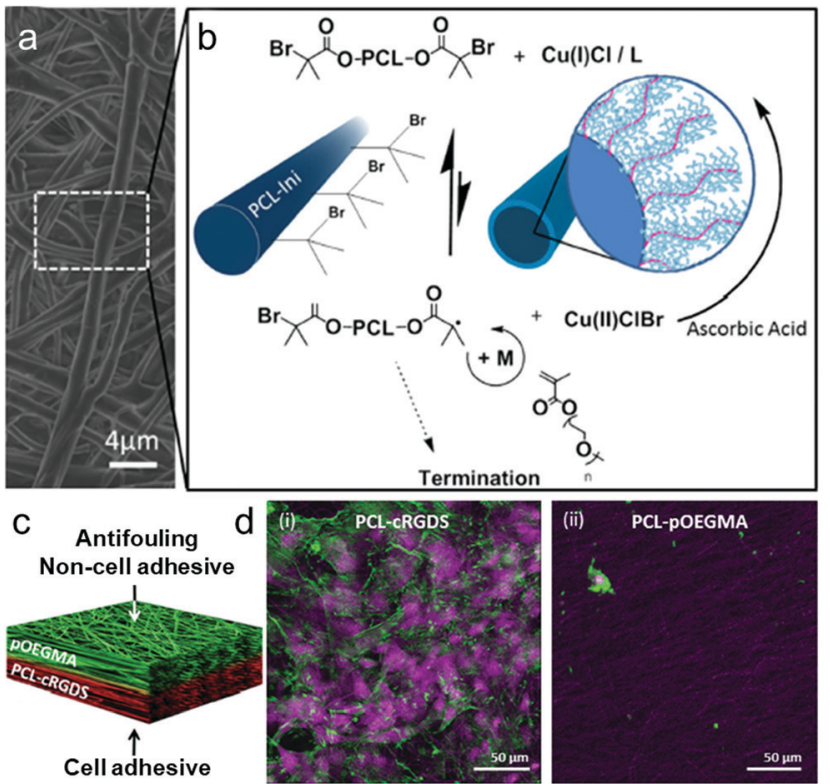

Fig. 4 Grafting of POEGMA bottlebrushes from prefunctionalized electrospun scaffolds to create an antifouling, non-cell-adhesive surface as part of a dual functional scaffold. (a) SEM micrograph of electrospun PCL-POEGMA fibres. (b) ARGET ATRP reaction scheme for polymerization of POEGMA from the PCL-Ini fibers with inset schematic images of PCL-Ini following electrospinning (left) and following polymerization of POEGMA from the fiber surface (right). ( $c$ and d) Schematic outlining and celladhesive/non-cell-adhesive properties of the bifunctional scaffold structure produced using layered electrospinning with postprocessing polymerization to create an antifouling PCL-POEGMA surface with an opposing cell binding PCL-cRGDS surface. Representative confocal microscopy images of bovine tenocytes cultured for 7 days on electropun PCL-CRGDS (i) and PCL-POEGMA scaffolds (ii). Cell nuclei stained with draq5 (purple) and actin with phalloidin (green). ${ }^{150}$

structure using layered electrospinning with postprocessing polymerization to create an antifouling PCL-POEGMA surface with an opposing cell-binding PCL-cRGDS (cRGDS: a cell-binding peptide motif of cyclic Arg-Gly-Asp-Ser) surface. ${ }^{150}$ Cell adhesion studies were carried out on this bilayered and dual-functionality scaffold with a cell-adhesive surface and an opposing antifouling non-celladhesive surface in zonally specific regions (Fig. 4).

Thian et al. incorporated nanohydroxyapatite (nHA) particles into the PCL matrix and prepared another typical dual-functional bilayer scaffold with improved mechanical properties via a combination of solvent and mechanical blending processes. ${ }^{158}$ This $\mathrm{PCL} / n \mathrm{HA}$ composite film could mimic the composition of tendon-bone interface tissue matrix which exhibited relatively soft tendon tissue and harder bone. These new strategies enable scaffolds that better mimic native tissue and organ structures with tailorable properties for many applications in tissue engineering and regenerative medicine.

Insulating polymeric scaffolds, owing to their superior biocompatibility, mechanical flexibility and processability, have been broadly used to promote nerve regeneration and guide the alignment of neurons or the differentiation of neurites in the desired orientation in neural interfacing. Nevertheless, is remains a challenge to understand the accurate mechanisms 
of how nerve cells sense and then respond to different surfaces of insulating polymer scaffolds/substrates. Moreover, much effort needs to be devoted to the development of new techniques for the modification of functional and/or re-orienting units to produce insulating polymer scaffolds with spatiotemporal control and finely tuned functions for a wider range of neural interfacing applications.

\subsection{Semiconducting polymers for photothermal or photoconductive stimulation of neurons}

Organic semiconducting polymers, due to the presence of delocalized and $\pi$-conjugated electrons, are a kind of macromolecular material with optical and electrical properties of semiconductors. ${ }^{159-161}$ In addition, semiconducting polymers could promote biocompatibility by coupling with biomolecules through surface functionalization. ${ }^{162-165}$ Compared to electrically insulating polymers, semiconducting polymers show additional optical properties, photoconductivity and photothermal effect that enable spatiotemporal control in neural interfacing using light irradiation as the stimulus. ${ }^{166}$ The past few decades have witnessed the rapid advances of semiconducting polymers in their synthetic chemistry, ${ }^{167,168}$ processing, device fabrications, ${ }^{169-172}$ and biomedical applications such as fluorescence imaging ${ }^{173-175}$ and photodynamic or photothermal therapy. ${ }^{78,176}$ For instance, Chen et al. prepared two types of small photoblinking Pdots using highly fluorescent polymers poly[(9,9-dioctylfluorenyl-2,7-diyl)-co-(1,4benzo-(2,1,3)-thiadazole)] (PFBT) and poly[2-methoxy-5-(2-ethylhexyloxy)-1,4-(1-cyanovinylene-1,4-phenylene)] (CN-PPV) to perform super-resolution fluorescence imaging of neuron cells. ${ }^{177}$ But only a few semiconducting polymers have been reported so far for neural stimulation (Fig. 5). This section focuses on the recent applications of semiconducting polymers for photothermal or photoconductive activation of neurons.

2.2.1 Semiconducting polymer nanoparticles for photothermal activation of neurons. Precise controlling of neuronal activity has profound effects on nerve repair. To that end, optogenetics has played an important role in the precise control of neuronal activity. ${ }^{179}$ However, the application of current optogenetic methods is largely limited by the need of transgenesis and not responsive to the near-infrared (NIR)
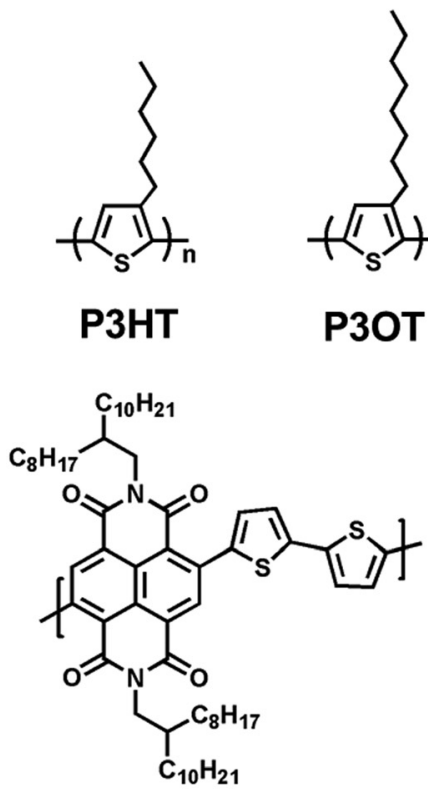

N2200

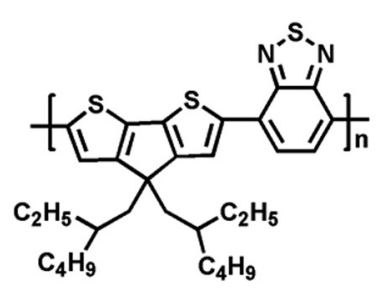

$\mathrm{SP}_{1}$

P3OT
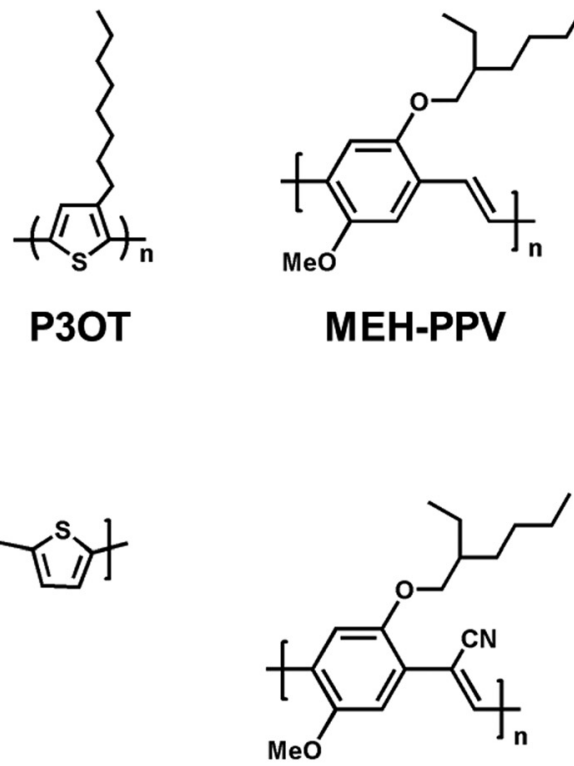

CN-PPV

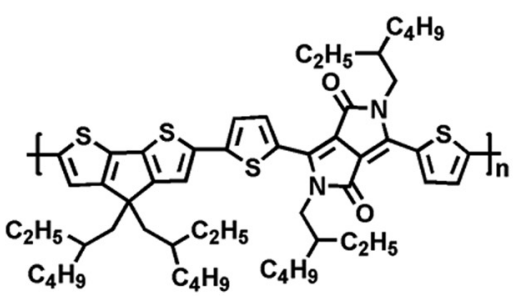

$\mathrm{SP}_{2}$

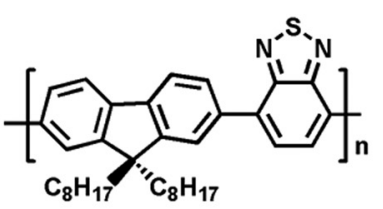

PFBT

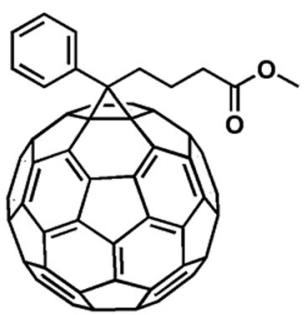

$\mathrm{PC}_{61} \mathrm{BM}$

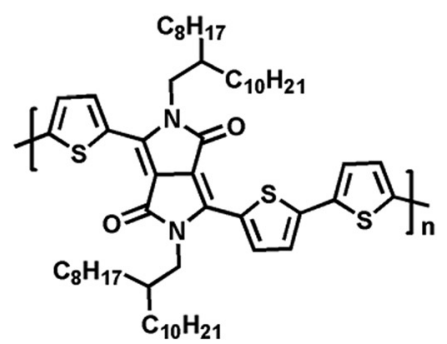

PDPP3T

Fig. 5 Molecular structures of representative semiconducting polymers and fullerene derivatives $\left(\mathrm{PC}_{61} \mathrm{BM}\right)$ for neural stimulation via photothermal $\left(\mathrm{SP}_{1-2}\right)$ or photoconductive effect. 
region that enables deep tissue penetration. To address these challenges, for instance, $\mathrm{Pu}$ and coworkers reported a nanobioconjugate of semiconducting polymer as an alternative to optogenetics. ${ }^{178}$ Semiconducting polymer nanoparticles (SPNs) were synthesized by conjugating anti-TRPV1 antibody on surfaces of colloidal nanoparticles composed of narrow band gap polymers $\left(\mathrm{SP}_{1}\right.$ or $\mathrm{SP}_{2}$, Fig. 5), which showed good biocompatibility with organisms to specifically activate the neuronal thermosensitive ion channel. The results confirmed that SPN as the photothermal nanomodulator was able to quickly increase the local temperature of TRPV1 ion channels to induce the photothermal activation of TRPV1, leading to specific $\mathrm{Ca}^{2+}$ influx of neuronal cells in a reversible and safe manner (Fig. 6). SPNs exhibit targeting, high photothermal conversion efficiency, and fast heating capability to reduce the probability of excessive heat to living cells.

2.2.2 Semiconducting polymer films for neuronal photoactivation. An alternative route to chemical, genetic and thermal approaches for neuron activation is the use of photosensitive extracellular electrodes. Compared to other approaches, this interfacial photoelectric activation could achieve communication between neurons and semiconducting polymers without external electric field and promote better heat dissipation. ${ }^{180,181}$ This facile tool provides a functional platform for activating neuronal photostimulation and cell growth. Photoexcitation of these semiconducting polymers would cause significant depolarization of the neuron as well maintain the specific mechanical, chemical, and biological properties of these materials. ${ }^{181-183}$ Nevertheless, rational selection of semiconducting polymers for light stimulation of neurons is important for maintaining their optoelectronic properties under biological conditions. ${ }^{184}$ In particular, oxygen and aqueous solutions may have a detrimental effect, such as oxidation and/or hydrolysis-induced degradation, on the involved polymers. A few examples of photovoltaic polymeric mixtures, poly(3-octylthiophene)/N2200 (P3OT/N2200), ${ }^{185,186}$ poly(3-hexylthiophene)/phenyl- $\mathrm{C}_{61}$-butyric-acid-methyl ester (P3HT/PCBM), poly[2-methoxy-5-(2'-ethylhexyloxy)-p-phenylene vinylene $] / \mathrm{C}_{61}$-butyric acid methyl ester (MEH-PPV/PCBM), ${ }^{187}$ and near-infrared tandem organic photodiodes ${ }^{188}$ have been tested and found to be stable under aqueous solution conditions. ${ }^{180}$ In contrast to the poor longterm biostability of silicon-based microphotodiode arrays incubated in saline solution, ${ }^{189}$ most of these semiconducting polymers (except polyfluorene derivatives such as poly[9,9-dioctylfluorenyl-2,7-diyl] (PFO)) and their composites with PCBM have shown remarkable biostability during incubation of the thin films in aqueous

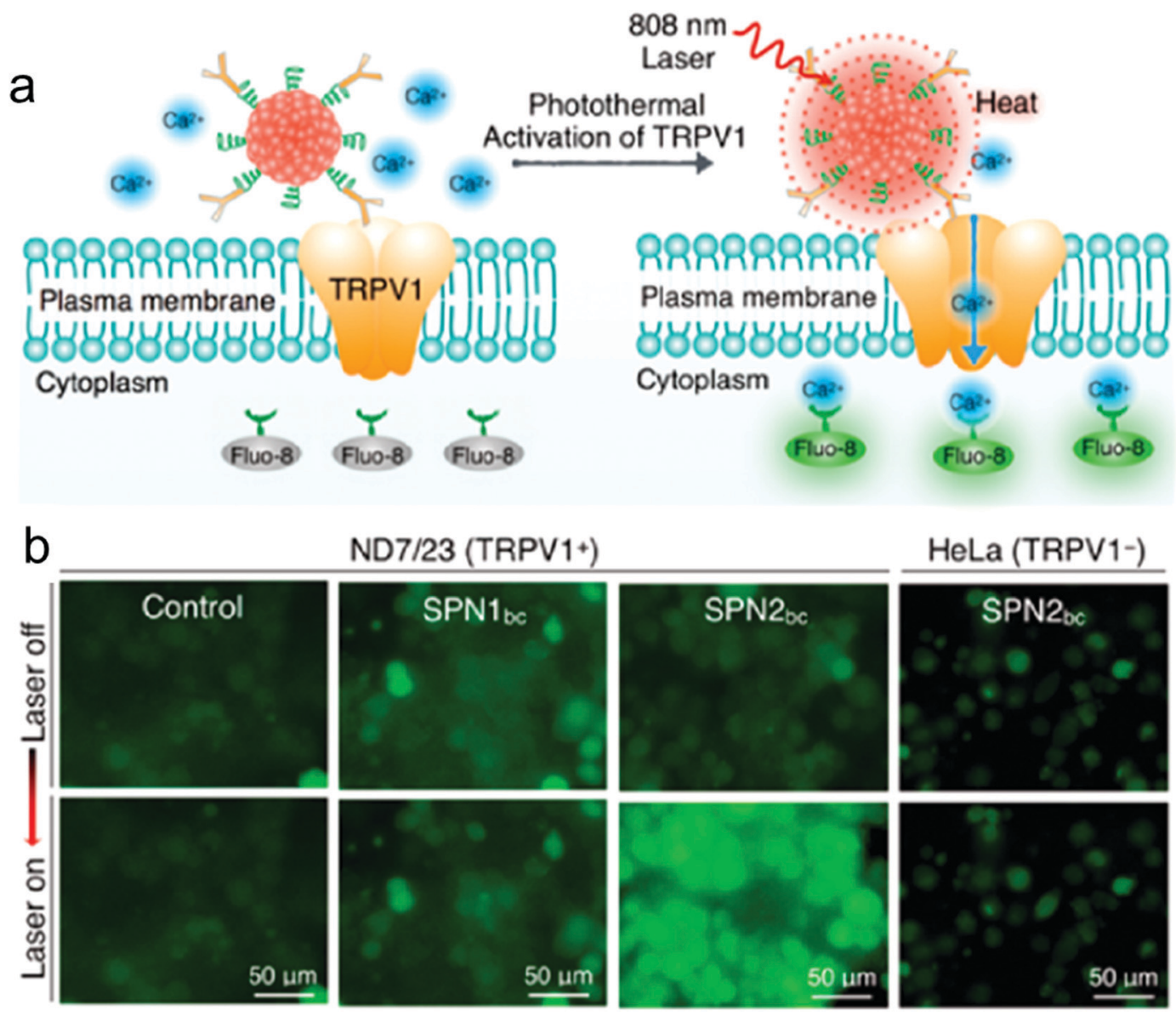

Fig. 6 NIR photothermal activation of the TRPV1 ion channels in mouse neuroblastoma/DRG neuron hybrid ND7/23 cells. (a) Schematic illustration of SPN controlled photothermal activation of $\mathrm{Ca}^{2+}$ channels in neurons. The intracellular concentration of $\mathrm{Ca}^{2+}$ was monitored in real-time by using Fluo- 8 as the indicator, which turned on its fluorescence upon binding with $\mathrm{Ca}^{2+}$. (b) Fluorescence images of ND7/23 or HeLa treated with SPN1bc or SPN2bc before and after laser irradiation at $808 \mathrm{~nm}\left(104 \mu \mathrm{W} \mu \mathrm{m}^{-2}\right)$ for $2 \mathrm{~s}{ }^{178}$ 
solutions or cell-culturing media. ${ }^{190,191}$ Such biostability combined with mechanical flexibility and optoelectronic properties makes semiconducting polymers attractive to bioelectronics including neural interfacing.

Ghezzi et al. demonstrated photostimulation of neurons by a polymeric mixture-based scheme (P3HT/PCBM), as illustrated in Fig. 7. In this bulk heterojunction (BHJ) structure, ${ }^{170,192}$ $\mathrm{P} 3 \mathrm{HT}$ is the electron donor, whereas PCBM is the electron acceptor. To achieve the photoactive neuronal interface, an ITO-coated glass substrate was spin-coated with the photovoltaic $\mathrm{BHJ}$ layer, followed by a poly-L-lysine coating to improve cell adhesion. The patch-clamp technique was used to record the electrical activity of primary rat embryonic hippocampal neurons, cultured on the polymer coated surface. In addition, neuronal network activity was characterized by extracellular recording of primary rat embryonic hippocampal neurons, cultured on a polymer coated ITO microelectrode array. ${ }^{180}$

Recently, Wu et al. studied photoconductive stimulation of neurons using multiscale-structured P3HT based biointerfaces (Fig. 8a). The micro/nano scale structures of P3HT used for neuronal interfacing and stimulation include self-assembled nanofibers with an average diameter of $100 \mathrm{~nm}$, electrospun microfibers with an average diameter of about $1 \mu \mathrm{m}$, and the lithographically patterned grooves with a width of 3,25 and $50 \mu \mathrm{m}$, respectively. Compared with the P3HT homogeneous film surface, self-assembled P3HT nanofibers promoted neuronal branches and new axon growth, while neurons cultured on P3HT microfibers showed longer and thinner neurites (Fig. 8b-f). ${ }^{78,193}$ These results suggest that two-dimensional patterned semiconducting polymer films can be a potential candidate for highperformance and stable optoelectronic synaptic devices for the photoconductive stimulation of neurons exhibiting functionally mature neuronal phenotypes and repairing injured peripheral nerves. In addition, the scale of the extracellular two-dimensional patterned semiconducting polymer matrix also influences cellular behaviors, including migration, growth, and differentiation of the neuronal cells. But further understanding of the mechanism at the biotic/abiotic interfaces requires development of new techniques for in situ monitoring of the neuronal response on the patterned films of semiconducting polymers under light irradiation.

Semiconducting polymers have made certain achievements due to their good biocompatibility, excellent light-harvesting properties and the capability of converting light to thermo/ electrical signals in neural interfacing. However, most of the recently reported semiconducting polymers used in neural
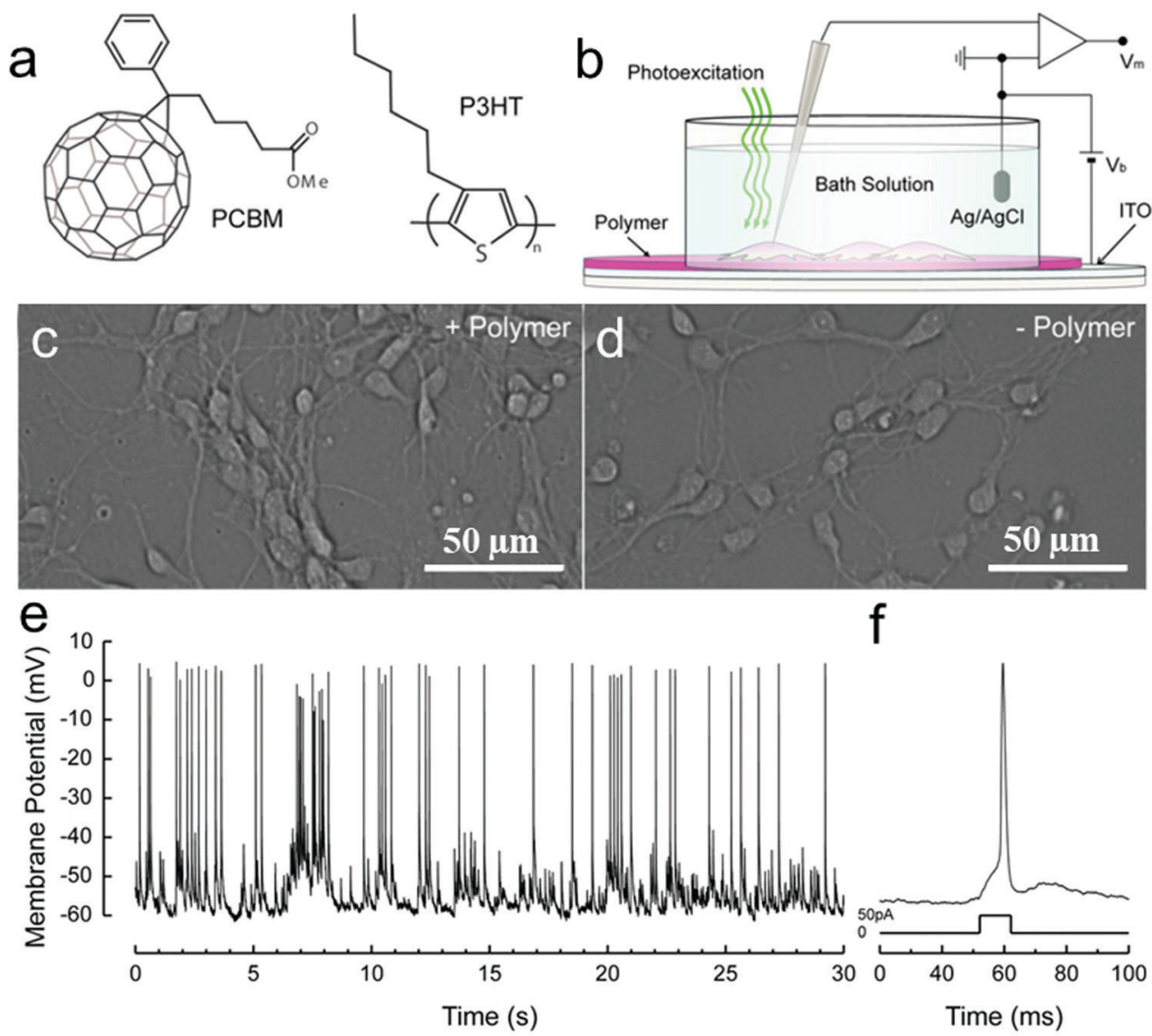

Fig. 7 Solid-liquid organic photodetector: the operation principle. (a) Chemical structures of rr-P3HT and PCBM. (b) Scheme of the photo-sensing interface, with the neuronal network grown on top of the polymer active layer during patch-clamp recordings. Hippocampal neurons cultured after 12 DIV on either poly-L-lysine treated ITO/rr-P3HT:PCBM devices (c) or control glass substrates covered only with ITO and poly-L-lysine (d). By adopting a standard patch-clamp technique, we recorded spontaneous activity (e) and action potentials induced by current injection into cultured neurons (f). ${ }^{180}$ 

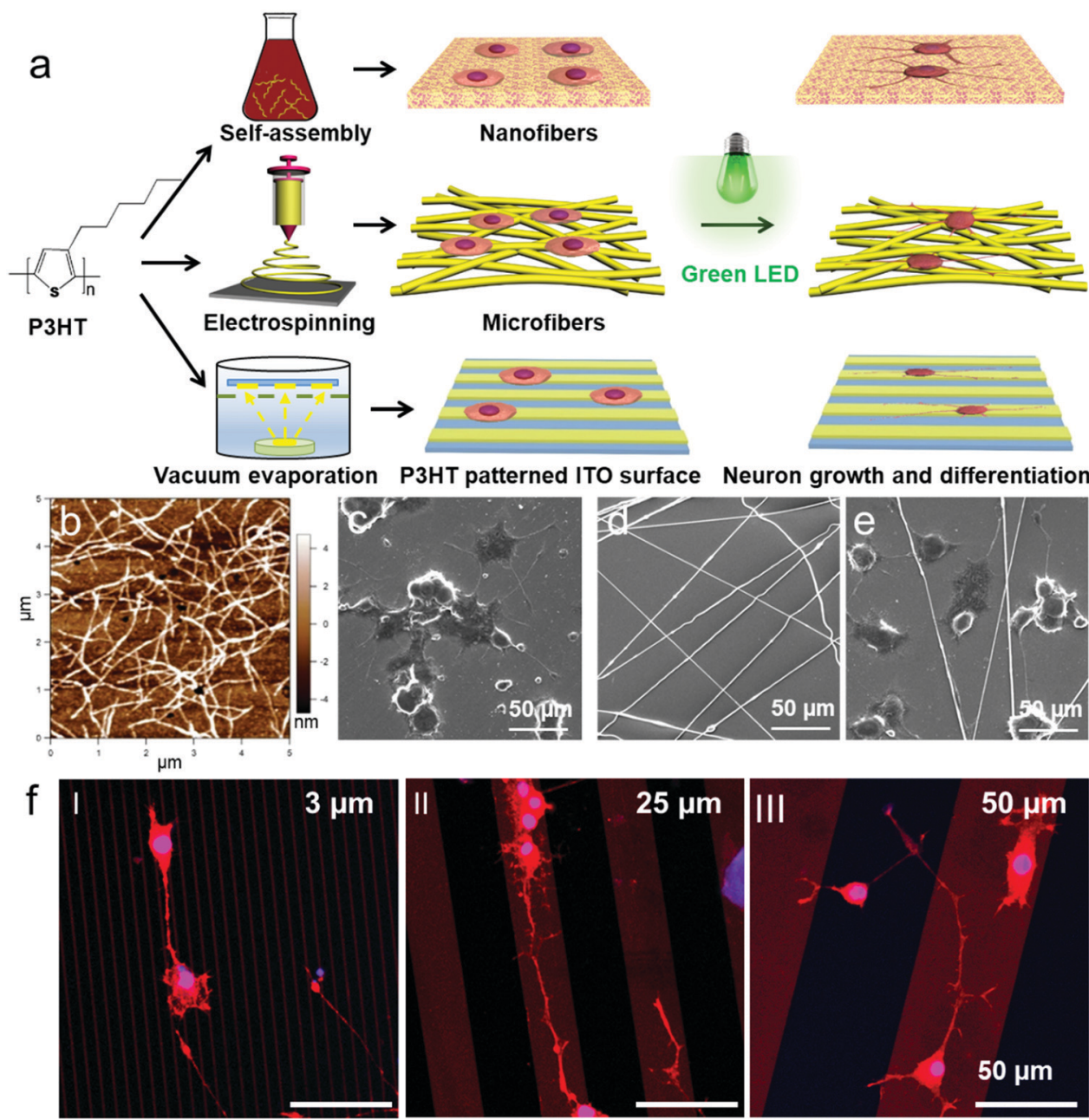

Fig. 8 (a) Schematic illustration of the preparation of P3HT micro/nanofibers and the P3HT patterned surface for PC12 cell culture. (b) AFM images of P3HT nanofibers. (c-e) SEM images of P3HT e-spun microfibers (d) and PC12 cells cultured onto the P3HT nanofiber substrate (c) and (e) P3HT microfiber substrate under LED irradiation. (f) Laser scanning confocal fluorescence microscopy images of PC12 cells cultured on ITO-coated glass surfaces patterned with 3,25 , and $50 \mu \mathrm{m}$ wide stripes of P3HT with LED irradiation. ${ }^{78}$

interfacing are intrinsically hydrophobic and require further surface modification to enhance the hydrophilicity and biocompatibility for interfacing with cells, tissues, and organs. The development of flexible and implantable semiconducting polymers for neural interfacing and electrophysiological application is a field that needs to be further explored. Furthermore, there is still much potential for exploring 3D semiconducting polymer scaffolds for cell culture, which remains rarely reported in neural interfacing.

\subsection{Conducting polymers for electrical stimulation of neurons}

The electrical stimulation on nerve cells plays an integral role in recent tissue engineering approaches, because bioelectricity in the human body is important to maintain normal biological functions such as wound healing and signaling of the nervous system. ${ }^{12,194,195}$ The properties of electrically conductive polymers include not only the physical and chemical properties of organic polymers but also the electrical conductivity, stable nano-topographical features, and high mechanical stability. ${ }^{196-198}$
These properties of conducting polymers have been used to promote the local transmission of electrical stimulus, the growth of cells and tissue repair. ${ }^{199-205}$

The early work of Langer and coworkers has proved that electrically conducting polypyrrole (PPy) could control surface charge density due to reversible electrochemistry to stimulate neurite outgrowth. ${ }^{206}$ Since then, a variety of other conducting polymers such as polyaniline (PANi), polythiophene (PT), poly(3,4-ethylenedioxythiophene) (PEDOT), and their derivatives and composites have been reported as substrates for cell adhesion, outgrowth, and proliferation at the polymer-tissue interface through electrical stimulation. ${ }^{72,207-212}$

In this section, we review the preparation, mechanism, and neural application of conducting polymers in three groups: one dimensional (1D), two-dimensional (2D), and threedimensional (3D) micro-/nano-structured materials. We particularly focus on the strategies used for the biocompatibility improvement of these conducting polymers and also the integrated novel technologies for fabrication of electrically 
conducting scaffolds, such as electrospinning, electrochemical polymerization, and in situ vapor phase polymerization.

2.3.1 Micro/nanoscale fibers and tubes of conducting polymers for neural stimulation. 1D conducting polymer materials such as polymer nanofibers or nanotubes were used in neural interfacing. ${ }^{215}$ Among them, polymeric fibers with sizes in the nanometer and micron ranges have recently become very popular materials for tissue engineering applications. ${ }^{216}$ Specifically, 1D nanofibrous scaffolds based on conductive polymer PANI and its derivatives have shown the effect of electrical stimulation on nerve stem cells (NSCs). ${ }^{217}$ Nanofibers of PANI blended with spinnable polymers poly(e-caprolactone)/gelatin (PG) solution (PANI/PG) and prepared by electrospinning facilitated the growth of nerve cells. ${ }^{213}$ The formation of the polymeric blend system is uniform and there are no beads on the nanofibers. Culturing NSCs on PANI/PG nanofibrous scaffolds with electrical stimulation led to longer neurite length and higher cell proliferation.

PEDOT as the derivative of polythiophene and another promising conducting polymer exhibits particularly low electrochemical impedance and tissue-friendly characteristics in vivo for implantable neural electrodes. For instance, Abidian et al. reported that PEDOT nanotubes promoted neurite outgrowth and dorsal root ganglion (DRG) cells had better attachment, less branches, and longer neurites on PEDOT nanotubes. ${ }^{218}$ However, PEDOT produced by those previous approaches could not contact with the carrier PLGA template well to obtain aligned PEDOT fibers. Thus, it is difficult to obtain completely discrete fibers. Martin et al. reported a facile, robust method for the fabrication of aligned PEDOT nanotubes through electrospinning and oxidative chemical polymerization (Fig. 9a). ${ }^{214}$ This emerging approach chooses PLGA polymers loaded with EDOT monomer as reactants and $\mathrm{FeCl}_{3}$ as an oxidative catalyst using electrospinning technology to polymerize PEDOT-PLGA fibers consisting of a PEDOT coated shell and PLGA fiber core. Next, the PLGA fiber core and residual EDOT were removed by immersing the PEDOT-PLGA fibers in chloroform, resulting in hollow PEDOT tubes. The confocal image of DRG cultured on PEDOT tubes shows that DRG sensory neurons attach to PEDOT fiber bundles and grow neurites along the long axes of the tubes (Fig. 9b). In addition, spindle-shaped Schwann cells grown out of the body of the DRGs precisely follow the alignment direction of PEDOT tubes (Fig. 9c).

Xia and coworkers prepared uniaxially aligned conductive PCL-PPy or PLA-PPy core-sheath nanofibers by electrospinning and aqueous polymerization to promote adhesion of DRG cells on core-sheath nanofibers and enhance outgrowth of neurites. ${ }^{219-221}$ Furthermore, the surface functionalization strategy for electrically conducting PEDOT microfibers may
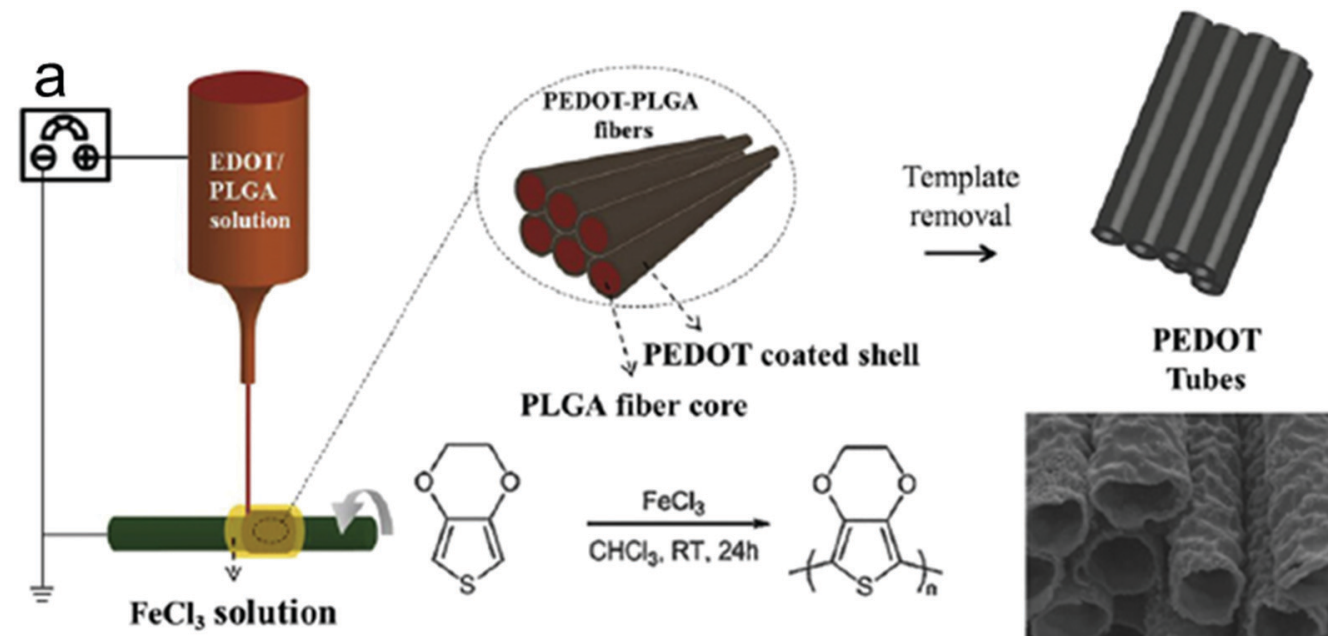

PLGA fiber core
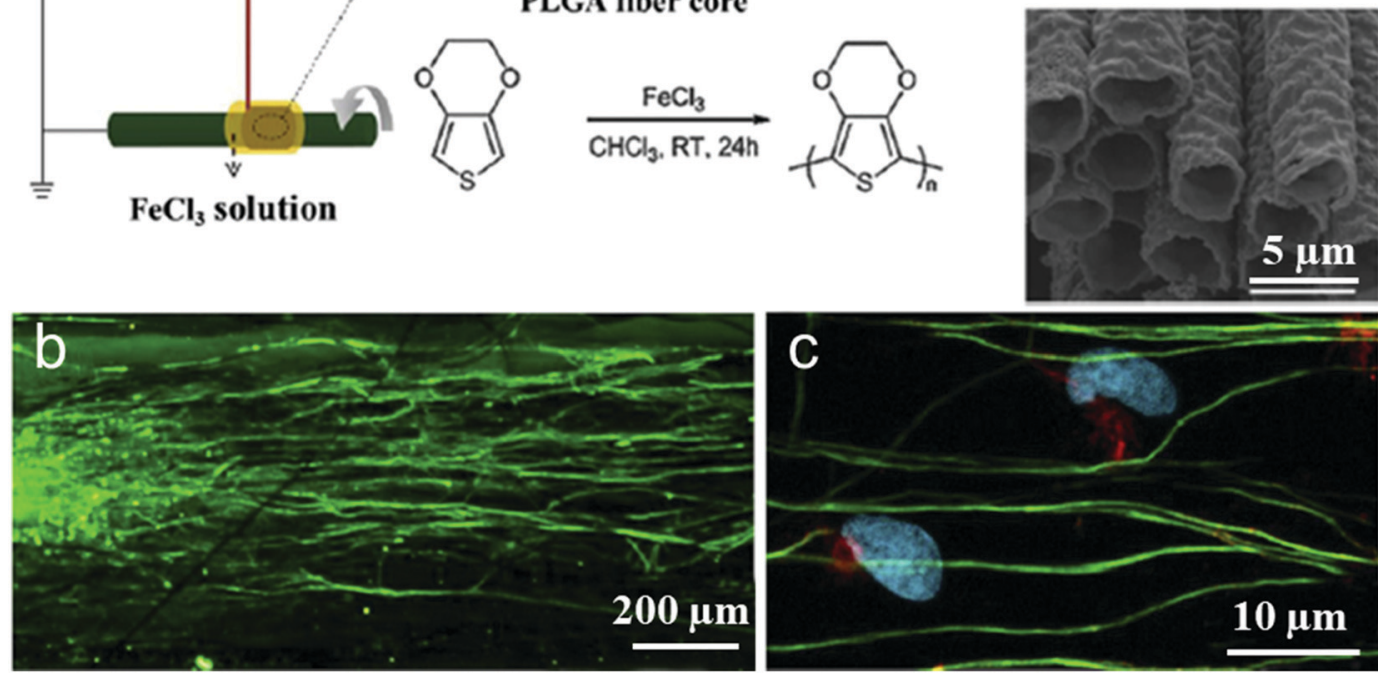

Fig. 9 (a) Schematic presentation of the synthesis of PEDOT microtubes using aligned electrospun PEDOT shell/PLGA core microfibers as templates. ( $b$ and $c$ ) Confocal fluorescence images of DRG neurites cultured on the aligned electrospun PEDOT microfibers. Beta-tubulin (green), a structural component of neurons, indicates that the DRG neurites followed the direction of fiber alignment (horizontal). Schwann cells are identified by co-localization of neural marker s100 (red) and DAPI (blue). ${ }^{213}$ 
provide a powerful tool for controlling neuronal growth and regeneration. Collazos-Castro et al. investigated PEDOT:PSS-coMA-coated electroconducting microfibers which could promote proliferation and migration of CNS glial progenitor cells with electrical stimulation. ${ }^{22}$ PEDOT is not only made into $1 \mathrm{D}$ microfibers in neural tissue engineering. ${ }^{67}$ In the previous work of $\mathrm{Lu}$ and coworkers, it also forms an interpenetrating PEDOT/ PSS-PVA/PAA network. This conductive 2D polymer hydrogel interpenetrating polymer network (IPN) film has the advantage of manufacturing a low impedance and biostable interface for implantable optical fiber-electrode arrays. ${ }^{223}$ Liu et al. synthesized electrically conductive aligned-nanofibers (PPy-G/PLGA) for optical regeneration of retinal ganglion nerve cells (RGCs). ${ }^{224}$ Using the aligned nanofibers as electrical electrodes, the stimulated RGC cell outgrowth was well guided and electrical stimulation led to $137 \%$ improvement in cell length. These results indicate that polypyrrole functionalized graphene enhanced electrical conductivity of the fiber, which significantly accelerated RGCs proliferation, differentiation, and enhanced antiaging effect of RGCs under electrical stimulation.

Further in vivo studies of these electrically conductive polymeric 1D micro/nanoscale fibers and tubes in animal experiments are needed in the future, in order to demonstrate the real potential of these materials and structures for clinical applications in guided nerve repair.

2.3.2 2D films of electrically conducting polymers for neural stimulation. In neural tissue engineering, traditional bioelectronic devices such as metal-based needles would initiate adverse reactions such as implant-induced inflammation and immunogenic scarring to the human body, and these disadvantages would cause difficult interfacial communication between bioelectronic materials and neural cells. ${ }^{62} 1 \mathrm{D}$ fiber-like or tubular structures of conducting polymers have been effective to alleviate the above problems. However, compared to $1 \mathrm{D}$ micro/nanoscale fibers and tubes, 2D films of conducting polymers could provide better adhesion and wider growth space for neurons. In addition, 2D films have the advantage of mimicking the cell membrane with improved biocompatibility. ${ }^{226}$

Inspired by the characteristics of phospholipid bilayers and specific binding of cell membranes, Zhu et al. designed and synthesized 2D biomimetic PEDOT films composed of two different new EDOT monomers, ${ }^{225}$ zwitterionic phosphorylcholinefunctionalized EDOT (EDOT-PC) which resists non-specific binding to proteins and cells, and maleimide-functionalized EDOT (EDOT-MI) for covalent binding of peptide sequences recognized by integrin (Fig. 10a). A home-designed device
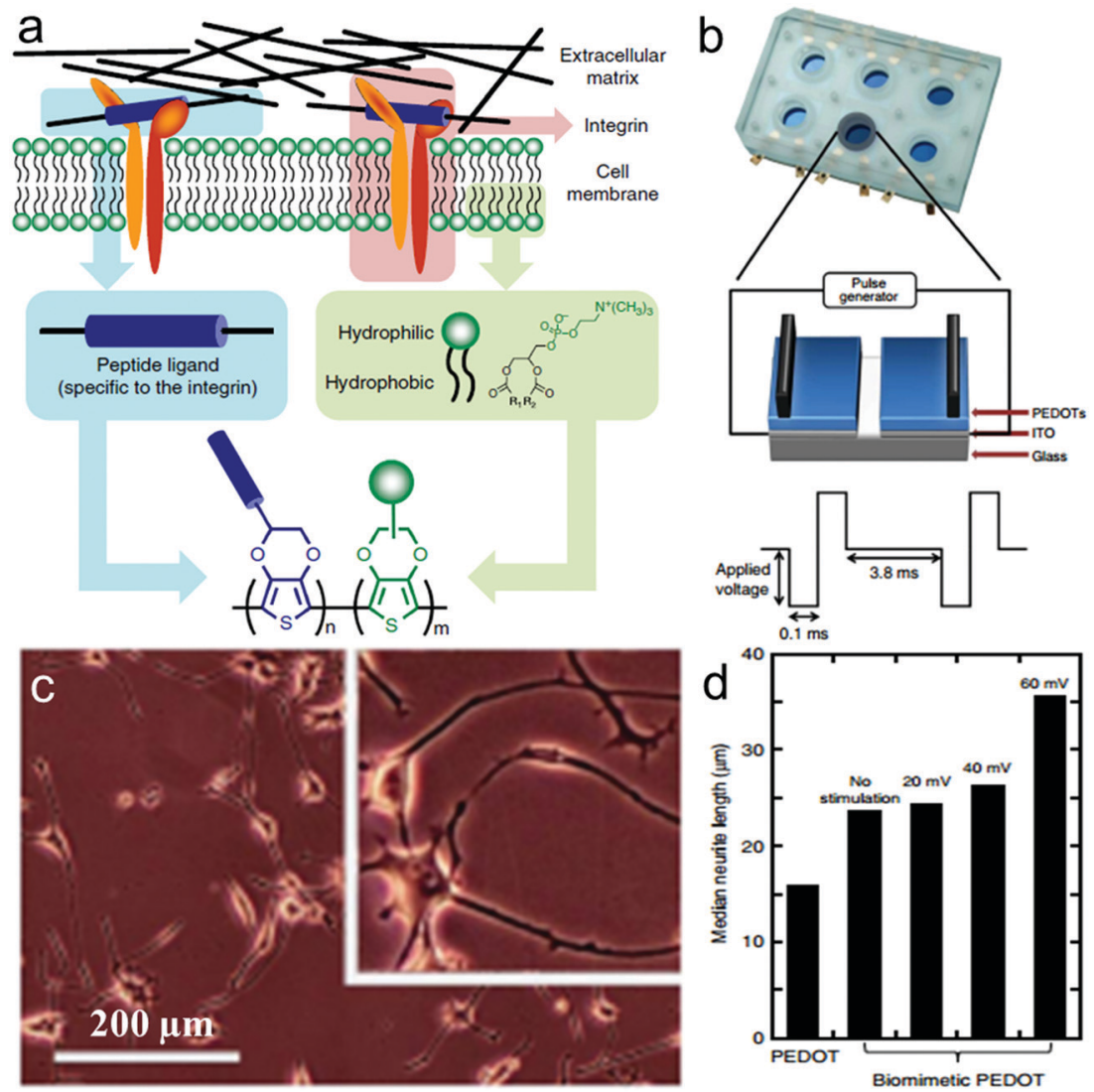

Fig. 10 Electrically stimulated cell behavior on biomimetic PEDOTs. (a) Schematic representation of the approach leading to the design of the target conducting polymer, mimicking the interactions between the cell membrane and the ECM. (b) Schematic representation of the device used for cell growth with applied electrical stimulation. (c) Microscopy images of differentiated PC12 cells cultured in NGF-supplemented medium for 5 days on the biomimetic PEDOT film with applied pulsed electrical stimulation at an amplitude of $60 \mathrm{mV}$. (d) Median neurite length of PC12 cells on PEDOT and biomimetic PEDOT in the absence and presence of applied pulsed electrical stimulation at amplitudes of 20,40 and $60 \mathrm{mV}$. $^{225}$ 
consisting of ITO-coated glass substrate and the electrodeposited biomimetic PEDOT films was used to observe the electrically stimulated cell behavior (Fig. 10b). ${ }^{227}$ Differentiated PC12 cells in NGF-supplemented medium for 5 days showed improved adhesion and differentiation on the biomimetic PEDOT films, under applied pulsed electrical stimulation at an amplitude of $60 \mathrm{mV}$, and more than 99\% of PC12 cells survived (Fig. 10c). Meanwhile, the median neurite length of PC12 cells increased obviously in this case (Fig. 10d).

The above biomimicking PEDOT films fabricated by a pair of monomers of EDOT-PC and EDOT-MI are expected to achieve higher conductivities, and efficient and long-term electrical communication at the interface with neuronal cells. The most important feature of these biomimetic 2D films is that they can resist nonspecific binding of proteins and cells to diminish immunogenic scar formation and inflammation, thereby extending the lifetime of the device. Using these materials, electrical stimulation and differentiation of neuronal cells can be enhanced efficiently, thus proving them suitable substrates for neuronal cells/tissue regeneration and recovering of damaged biofunctions.

Some other 2D PEDOT films have also been utilized to overcome neuron-functional deficits associated with neurological disease in human beings. ${ }^{228}$ For instance, Lu et al. utilized striped microelectrode arrays composed of alternating PEDOT and reduced graphene oxide (rGO) to fabricate two dimensional organic bioelectronic devices via lithography technology and the organic bioelectronic devices have been demonstrated to spatially and temporally manipulate the location and proliferation of the neuron-like PC12 cells. ${ }^{229}$ PEDOT doped with poly(styrene sulphonate) (PSS) can also be used as an organic electronic ion pump to mediate electronic control of the ion homeostasis in neurons ${ }^{230}$ and culture them to form neural networks. ${ }^{231-233}$ PEDOT, PPy and PANI have also been utilized as a bioelectronic interface electrode separately to provide electrical stimulation enhancing PC12 cell differentiation and neurite outgrowth. ${ }^{234-237}$ PEDOT has also been applied to form polymers around living neural cells to facilitate the establishment of long-term, bi-directional communication between host cells and implanted microelectrode devices. ${ }^{238}$ Povlich et al. synthesized carboxylic acid-functionalized EDOT (EDOTacid) monomer to be copolymerized with EDOT monomer and then bound with peptide, forming peptide functionalized PEDOT (PEDOT-PEDOTacid-peptide) films which induced 3-9 times increased adhesion of primary rat motor neurons. ${ }^{239}$

2.3.3 3D scaffolds of electrically conducting polymers for neural stimulation. Although many intricate methods have been developed to generate complex two-dimensional (2D) patterns and gradients of biochemical and mechanical cues, 2D culture conditions may not be appropriate for certain types of cells. Therefore, there is a need to create synthetic materials and 3D structures that resemble the extracellular matrix (ECM) to support three-dimensional (3D) cell culturing and tissue regeneration. ${ }^{240-243}$ Among them, hydrogel-based substrates or scaffolds have attracted growing interest in neuroscience, as hydrogels exhibit biocompatibility, and the mechanical buffering ability to mitigate the inflammation at the biotic/ abiotic interface caused by mechanical mismatch. ${ }^{244,245}$

Soft hydrogels that can provide microenvironments akin to natural ECM have been shown to support neurite extension for cell proliferation, differentiation and axon extension. ${ }^{247,248}$ Although these soft hydrogels show advantages such as a similar environment for the extracellular matrix for cell regeneration under electrical stimulation, their limited mechanical strength, which may result in collapse under stress, needs to be addressed for certain biomedical applications.

3D conductive materials showed better biocompatibility, supporting ability, dynamic mechanical properties and biochemical functionalities in neural interfacing. To a certain extent, these 3D electrically conductive nanoporous materials could overcome the shortcomings above to make them promising materials for application in nerve repair. 3D functional polymeric scaffolds of novel biomaterials have been proved to strongly support cell culture and tissue regeneration. During implantation over the course of nerve regeneration, 3D nerve guidance scaffolds have a better advantage in tear-resistance, biodegradability, sterilizability, and shape retention. ${ }^{12}$

As a consequence, 3D cell-culturing models better resembling biological microstructures, dynamic mechanical properties, and biochemical functionalities have recently garnered lots of attention to promote cell differentiation and tissue organization. ${ }^{249}$ Several attempts focusing on biomacromolecules such as nanoporous cellulose gels (NCG) as a template for in situ polymerization are beneficial for facile fabrication and remarkable mechanical strength of conducting polymers. For instance, Shi et al. presented 3D electrically conductive nanoporous materials synthesized in situ from pyrrole vapor in an NCG matrix through oxidative initiation. ${ }^{246}$ With $\mathrm{FeCl}_{3}$ oxidants, the supplied pyrrole vapors polymerized into PPy nanoparticles (Fig. 11b). The in situ vapor phase polymerization resulted in the NCG/PPy composite aerogels through four processes (Fig. 11a) to obtain NCG/PPy composite alcogel with different PPy contents. PPy adhered to the cellulose nanofiber surface as small particles could increase the conductivity of cellulose nanofibers and enhance cell adhesion on the PPy-coated cellulose nanofibers. ${ }^{250}$ Under different conditions, the composite hydrogels can still maintain superior mechanical strength (Fig. 11c-e). Xu et al. reported the differentiation of neural stem cells (NSCs) to neural and glial progenitors on highstrength hydrogels. ${ }^{251}$ Comparatively, Kim et al. demonstrated that PEG-PEDOT:PSS treated with $\mathrm{H}_{2} \mathrm{SO}_{4}$ optimized conductive hydrogel could support cell adhesion and proliferation without compromising the electrical and physicochemical properties of the hydrogels. ${ }^{252}$

In addition, as nanostructured conducting polymers, NCG/ PPy composite aerogel can also provide a suitable environment for damaged nerve cells to adhere, regenerate and recover. However, they also face the same problem of implant-induced inflammation and scar formation. When culturing on NCG/PPy composite aerogel with the surfactant dodecyl benzenesulfonic acid (DBSA) dopant, PC12 cells exhibit better attachment, more regeneration and longer neurites. ${ }^{246}$ 


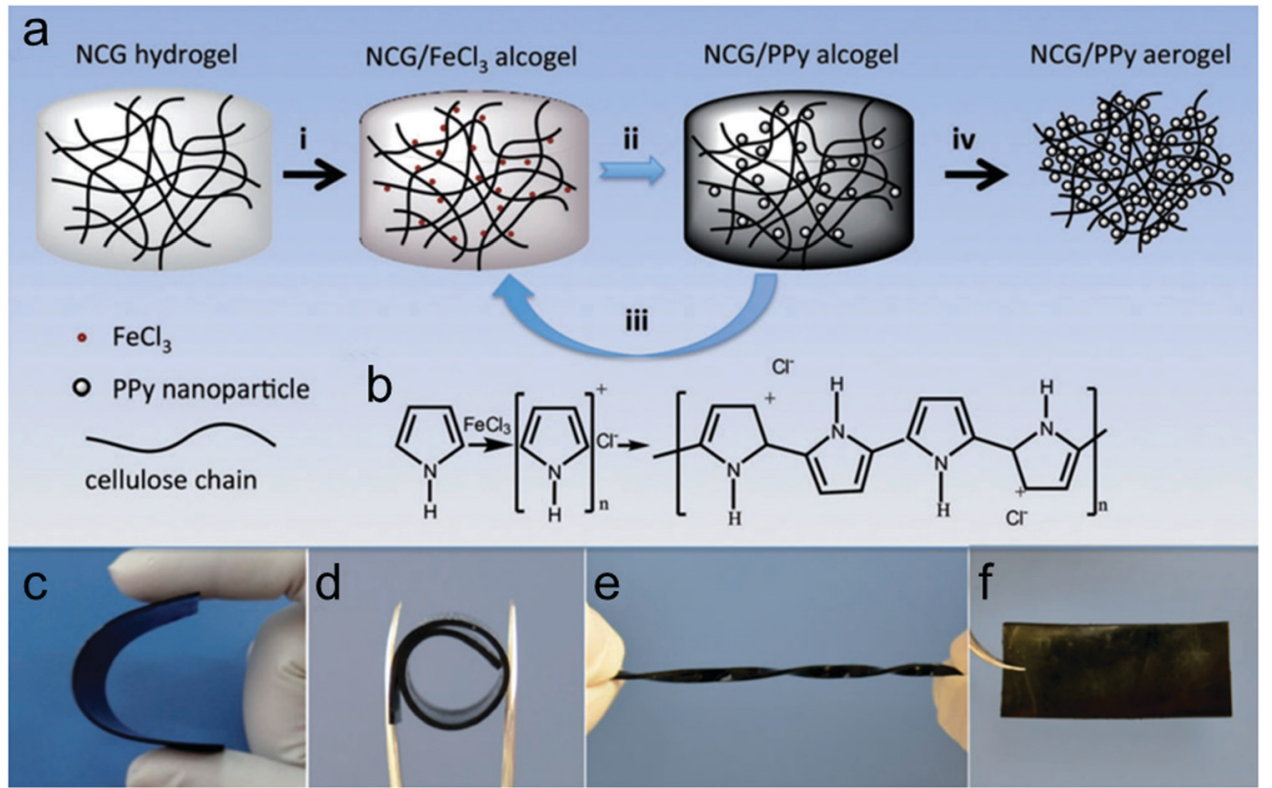

Fig. 11 (a) Preparation of NCG/PPy composite aerogels. (i) The NCG hydrogel with an interconnected nanofibrillar network is solvent exchanged with ethanol, and then impregnated with a solution of $\mathrm{FeCl}_{3}$ in ethanol to form the $\mathrm{NCG} / \mathrm{FeCl}_{3}$ alcogel. (ii) PPy nanoparticles are formed by in situ vapor-phase polymerization of pyrrole monomers supplied as vapor, giving the NCG/PPy-1 composite alcogel. (iii) Repeating the second step two or three times gives NCG/PPy-2 and NCG/PPy-3 composite alcogels, respectively. (iv) Drying with supercritical $\mathrm{CO}_{2}$ gives the NCG/PPy composite aerogel. (b) Schematic representation of pyrrole polymerization with $\mathrm{FeCl}_{3}$. Macroscopic views of NCG/PPy-3 composite hydrogels under (c) bending (63 mm $\times 28 \mathrm{~mm} \times$ $0.9 \mathrm{~mm}$ ), (d) rolling (internal diameter of $10 \mathrm{~mm}$ ), and (e) torsional loading $(63 \mathrm{~mm} \times 5 \mathrm{~mm} \times 0.9 \mathrm{~mm}$ ), and (f) the NCG/PPy-3 composite aerogel $(63 \mathrm{~mm} \times 28 \mathrm{~mm} \times 0.9 \mathrm{~mm}){ }^{246}$

In summary, electrically conducting polymer scaffolds with appropriate space structures for neuronal tissue engineering can deliver local electrical signals to cells, enabling us to achieve efficient tissue regeneration and control over cell behavior. Nevertheless, the poor biocompatibility and biodegradability of pure conducting polymer scaffolds still restrict their clinical application in vivo. Thus, in the future design of conducting neural engineering scaffolds, bioactive materials can be introduced into the development of degradable biopolymer blends and composites for the regeneration of clinically relevant electrical-sensitive tissues. Other limitations of the electrically conducting polymers and scaffolds for neuronal stimulation, including the requirement of external power sources and often complicated and invasive wiring, remain to be addressed in future research.

\section{Detection of neuronal response}

How to detect neuronal response to electrical or optical stimulation or topographical feature of substrates is an important topic on nerve repair at interfaces with functional organic polymers. ${ }^{31}$ In the following sections, we review methods and techniques regarding detection of neuronal responses, including fluorescence microscopy to observe single neuronal cells, use of voltage-sensitive dyes to observe membrane voltage change, microelectrode arrays (MEAs), semiconducting field-effect transistors (FETs) and patch clamp chips (Fig. 12).

\subsection{Fluorescence microscopy of single neurons upon stimulation}

Fluorescent reporters composed of an archaerhodopsin-derived voltage sensor with fused fluorescent proteins have been widely reported for characterization of dysregulated membrane voltage and neuronal action potentials. Voltage-dependent nonradiative quenching of the fluorescent protein depends on the voltage-induced shifts in the acid-base equilibrium of the Schiff base, which means that the characteristic fluorescence could be regulated by change of the membrane voltage. Zou et al. presented genetically encoded fluorescent reporters with bright multicolor to detect neural function. ${ }^{253}$ Genetically encoded voltage indicators (GEVIs) of multicolor fluorescence can robustly report action potentials (APs) in cultured neurons and distinguish the activity of excitatory and inhibitory neurons through multiplex voltage imaging. Voltage can not only modulate the fluorescent brightness but also the efficiency of Förster resonance energy transfer (FRET). Although it is difficult to directly measure the voltage-depended absorption spectra of an Arch mutant in a single cell, the fluorescence could be modulated by a voltage-dependent shift in the absorption spectrum of the rhodopsin (Fig. 13a). Citrine, mOrange2, mRuby2, ArcLight, ASAP1 and QuasAr2 eFRET GEVIs all have efficient trafficking to the plasma membrane. The fast and transient fluorescence response of all those reporters in human embryonic kidney (HEK) cells is presented in Fig. 13b. In addition, far-red fluorescence reporters can enable simultaneous, bright multicolor imaging of cell APs. For instance, QuasAr2-based eFRET 

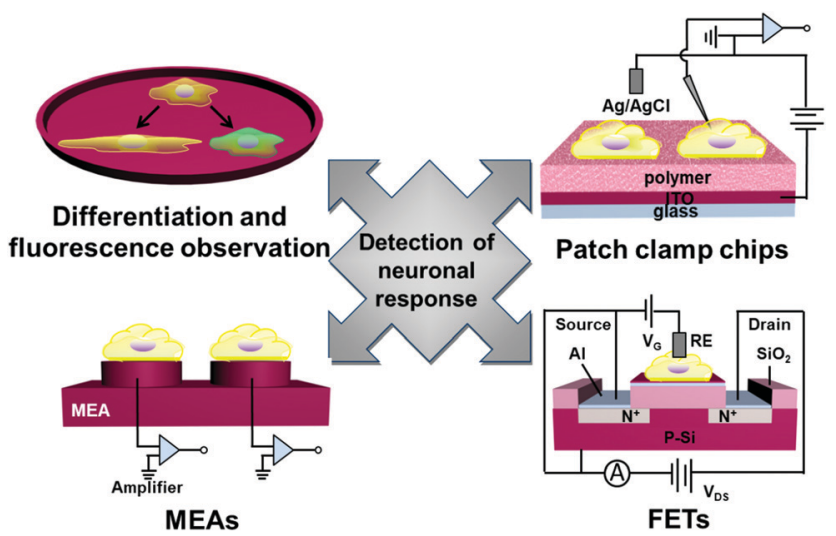

Patch clamp chips

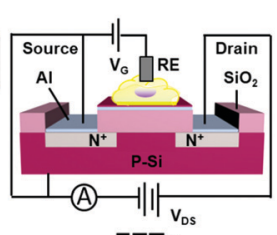

FETs

Fig. 12 Schematic summary of four kinds of detection methods for neuronal response.

GEVIs have an advantage in sensitivity, speed, and photostability at the far-red end of the spectra. However, the QuasAr2-based eFRET GEVIs have a limitation that they need intense laser illumination to efficiently detect neural function. Hochbaum et al. developed two archaerhodopsin-based sensitive, fast and spectrally orthogonal GEVIs which showed enhanced brightness and voltage sensitivity for genetically targeted simultaneous optical perturbation and measurement of membrane voltage. ${ }^{255}$
Moreover, Kralj et al. used a microbial rhodopsin protein, Archaerhodopsin 3 (Arch), to detect electrically triggered APs. ${ }^{254}$ These microbial-based voltage indicators could achieve reliable optical detection of single APs in mammalian neurons. When modulating one cell membrane potential by whole-cell voltage clamp, it could be seen a clear image of the target cellular structure (Fig. 13c). In order to improve imaging capability of neural response activity, Chen et al. developed a new class of GEVIs, GCaMP6, which can detect single action potentials and orientation-tuned synaptic calcium transients in individual dendritic spines of the mouse visual cortex. ${ }^{256}$

Two series of fluorescence indicators above facilitate detecting single trial APs and imaging of single cells distinguished from its neighbors. These fluorescence indicators and progressive optogenetic techniques may find widespread applications in brain-related research. Nevertheless, there still remain some key challenges and limitations of all fluorescence indicators, including efficient trafficking to the membrane, sensitivity, difficulty for application in vivo and so on.

\subsection{MEAs for detection of neural responses}

Microelectrode arrays (MEAs) are widely used to record and stimulate extracellular neuronal activity and they can analyze
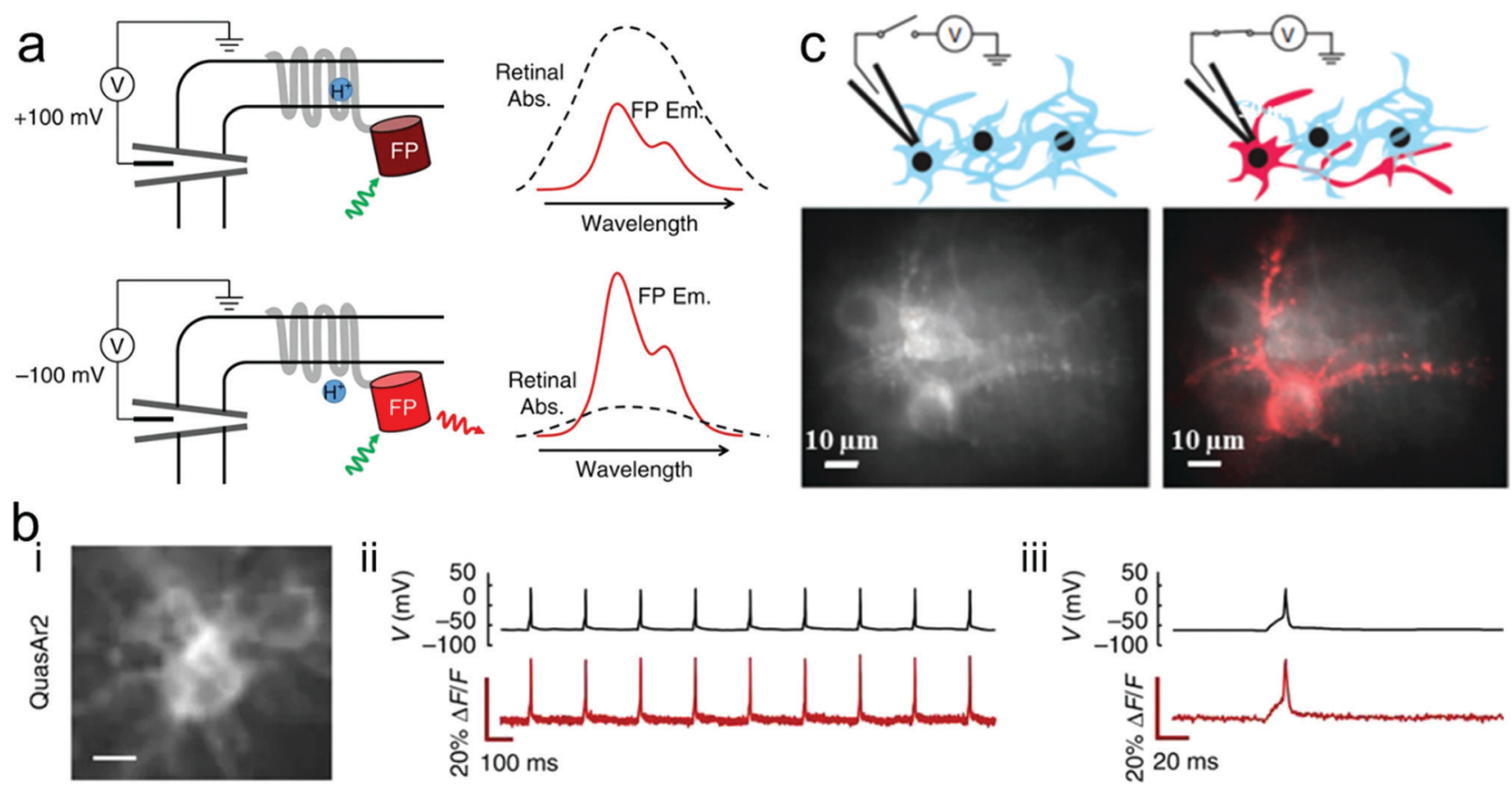

Fig. 13 (a) Proposed mechanism of voltage-dependent fluorescence in eFRET GEVIs. Voltage controls the protonation, and thereby the absorption spectrum, of the Schiff base joining the retinal to the protein scaffold. At a depolarizing (positive) voltage, the microbial rhodopsin has a protonated retinal Schiff base, which absorbs strongly with a peak near $600 \mathrm{~nm}$. The retinal absorption quenches the fluorescence of the appended fluorescent protein (FP). At hyperpolarizing (negative) voltages, the fluorescence is not quenched. Spectra shown are cartoons to illustrate the mechanism. (b) Single-trial recording of neuronal APs with GEVIs. The GEVI construct was expressed in primary rat hippocampal neurons under a CaMKIla promoter. APs were induced by current injections through a patch pipette. (i) Images of neurons expressing the indicated GEVI. (ii) Simultaneous patch clamp and fluorescence recordings of AP waveforms. Recording was acquired with laser illumination (200 W cm ${ }^{-2}$ for QuasAr2) at an exposure time of 1 ms. Fluorescence traces are presented without temporal filtering nor correction for photobleaching. (iii) Close-up showing single trial, unfiltered, electrically and optically recorded AP waveforms. ${ }^{253}$ (c) Application of a voltage to a single neuron caused an increase in fluorescence that distinguished a neuron from its neighbors (top). Time-average Arch fluorescence of multiple transfected neurons (left). Same field of view after membrane potential was modulated by whole-cell voltage clamp (right). Responsive pixels were identified via cross-correlation of the pixel intensity and applied voltage $\left(V\right.$, red) ${ }^{254}$ 
information from electrogenic cells in different regions of the same tissue over a long period of time. ${ }^{258,259}$ This technology has been utilized to measure external field potentials generated by clumps of beating cardiomyocytes derived from human embryonic stem cells (hESCs). ${ }^{260}$

For instance, Dipalo et al. integrated 3D plasmonic nanoantennas with MEA to combine nanoscale molecular sensing with electrical neural activity recordings. ${ }^{261}$ O'Shaughnessy et al. presented a portable, renewable neuron-based biosensor by culturing passaged neural stem and progenitor cells on MEAs to produce functional neuronal networks. ${ }^{257}$ They replaced the mammalian neurons with neural stem and progenitor cells to extend the life of neuronal networks on microelectrode arrays (MEAs). ${ }^{257}$ Neuroepithelial cells cultured in serum-free medium containing bFGF rapidly proliferated, differentiated into neurons and astrocytes and began to form multi-cellular clusters on MEAs (Fig. 14a and b). These results showed that a neuronal network could express spontaneous action potentials. Further tests for synaptic activity of neural progenitor-derived neuronal networks were treated with bicuculline, the NMDA ( $N$-methyl-D-aspartic acid) glutamate inhibitor (APV) and the non-NMDA glutamate antagonist (CNQX), respectively. The response of neuronal networks to bicuculline increased by about 96\%, while it decreased to APV and CNQX and the response to CNQX was almost zero. And the combination of bFGF and BDNF was proved to promote the generation of networks with spontaneous action potentials and more active synaptic activity (Fig. 14c). There is no doubt that neural stem and progenitor cells are suitable and renewable sources for portable biosensors, though a higher number of active channels in the neuronal networks on MEAs needs to be solved to improve biosensors.

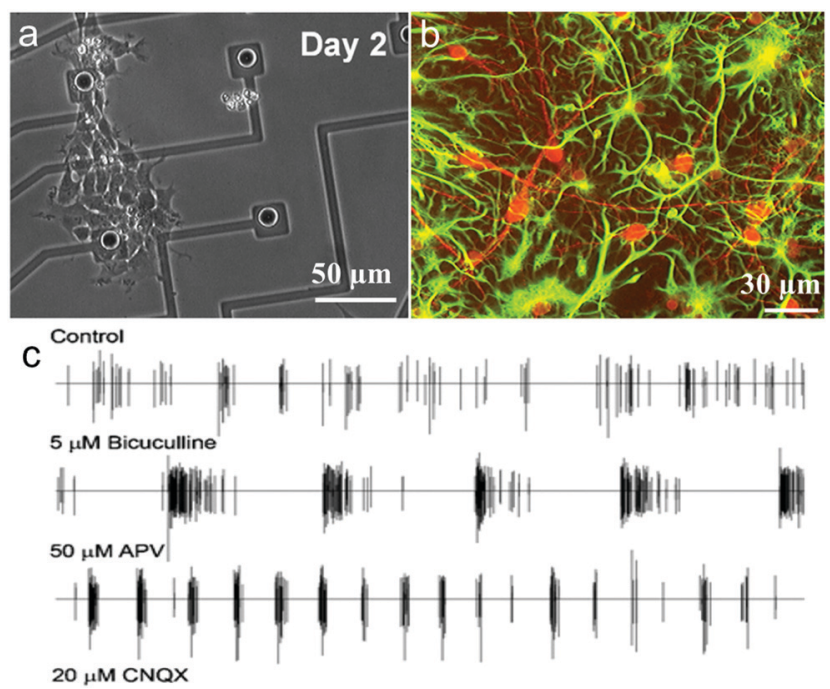

Fig. 14 Basic activities of neuronal networks on an MEA: (a) neuroepithelial cells isolated from the embryonic cortex expand and differentiate into neurons and astrocytes on the MEA, (b) cells differentiate into neurons and astrocytes, identified by double immunostaining, and (c) typical spike trains on an electrode of the network after several treatments, i.e., bicuculline, 6-cyano-7-nitroquinoxaline-2,3-dione (CNQX), and 2-amino-5-phosphonopentanoic acid (APV). Reprinted with permission from ref. 257.
In short, electrophysiological signals from neurons can be detected by recording electrical activity with innovative MEA bio-devices. $^{261}$ To improve the ability of MEAs of recording neuronal activity with increased sensitivity, exploring portability tools with better signal-to-noise ratio, more parallel readouts, higher spatial resolution and biocompatibility to reduce active channels in the neuronal networks remains a key issue for neuronal stimulation and recording.

\subsection{FET-based neuron sensors}

The rapid development of semiconductor micro- and nanotechnologies has stimulated the creation of new sensors and ion-sensitive field-effect transistors that detect both chemical and biological recognition processes, which can be widely applied in different fields including medicine, food technology, chemistry, biotechnology and so on. ${ }^{263,264}$ Organic field-effect transistors (OFETs) with specific surface chemistry, mechanical flexibility and high sensitivity to electrostatic potential are attractive for recording and stimulating neuronal network activity in vitro. ${ }^{262}$ Although organic semiconductors have lower charge mobility compared with inorganic counterparts, they can also exhibit fast and stable detection when operated in direct contact with aqueous solution. Therefore, OFETs have shown some advantages compared to inorganic transistors in detecting neuronal network activity in vitro. ${ }^{265-267}$

Cramer et al. presented an original water-gated organic field effect transistor (WGOFET) with pentacene as the semiconducting layer in the liquid-gated device architecture. ${ }^{268}$ The working principle and electrical connections with adhering cells of the liquid-gated pentacene transistor are presented in Fig. 15a. These devices, consisting of silicon oxide layer and deposition of pentacene films by high vacuum sublimation, show superior characteristics including a well-controlled morphology, biocompatibility and low-voltage operations. In the aqueous environment, they can promote adhesion and differentiation of stem cells into densely interconnected neuronal networks (Fig. 15b). Electrical stimulation verified that WGOFETs can stimulate and record extracellular signals of a population of mature neurons and the transistor is only sensitive to the
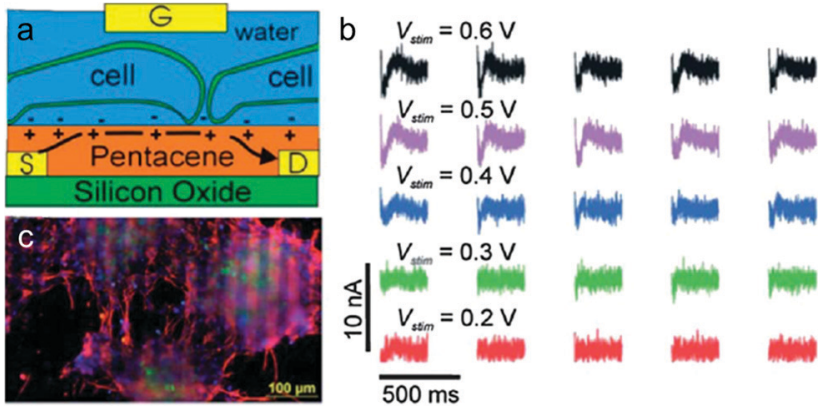

Fig. 15 Water-gated organic field effect transistors (WGOFET) neuronal transducer. (a) Schematic model of the device and interactions with adhering cells. (b) Drain current time traces recorded from a differentiated network after stimulation with various intensities. (c) Fluorescent microscopy image which indicates the formation of a functional neuronal network derived from murine stem cells on the transistor surface. ${ }^{262}$ 
stronger signals elicited by mature and differentiated neuronal stem cells (Fig. 15c). These WGOFETs enable stable operations in direct contact with water to stimulate, record and distinguish the differential conditions of neuronal stem cells. They are promising in monitoring the concentration of target molecules and nerve regeneration in nerve tissue engineering. Despite the advances in WGOFETs, long-term biocompatibility experiments in vivo have not been investigated and remain an open issue.

Electrophysiological recording of neurons and brain networks in vivo is critical to understand information transfer processes in neurons and the brain. However, it is difficult to extract information from noise because of the small electric potentials generated from neuronal circuits. ${ }^{270,271}$ While FET-based sensors could locally amplify and integrate SNR to measure signals from cell cultures, their poorly biocompatible oxide layer makes them limited to in vitro signal recording. The organic electrochemical transistor (OECT) was developed to directly combine the channel with electrolyte which permits ion transport between two layers. ${ }^{272}$ OECTs represent a type of attractive sensor for measuring electrophysiological signals and have better cytocompatibility and integration in neural interfacing. ${ }^{273-275}$ Malliaras and coworkers reported that OECTs composed of the PEDOT:PSS electrodes and stereo electroencephalography and electrocorticography (ECoG) probes could record electrophysiological signals of the epileptiform brain surface. ${ }^{269}$ The working principle and structure of ECoG probes is presented in Fig. 16a and b. ECoG probes are composed of a thick parylene film substrate, Au and PEDOT: PSS films that are photolithographically patterned into a plate. The devices show superior characteristics including high conformability, biocompatibility and low-operation voltage. The OECT-based ECoGs have been used in the in vivo experiment of epileptiform activity in rats, and can promote local amplification of signals and the recording demonstrates superior SNR of the ECoGs (Fig. 16d-g).

The use of OECTs is likely to detect and record small, local electrophysiological activities with superior SNR in vivo. Because of their biocompatibility and highly conformable nature, they are particularly suitable for epilepsy diagnosis, cortical mapping and so on. ${ }^{276,277}$

\subsection{Patch clamp chips for recording of neural responses}

In recent years, electrical stimulation has been used widely for many implantable devices to help restore motor activity, treat drug-resistant disease and restore sensory perception of nerve cells. After many efforts dedicated to overcoming the challenges between electrodes and neuronal tissues, another innovative approach, neuronal photostimulation, has shown much potential in photo-physiological neural engineering. It has been shown that photoconductive-stimulation could extracellularly excite any neuron in a network and activity-dependent cellular processes can be dynamically monitored when photoconductive stimulation was used with fluorescence imaging of various molecular probes. ${ }^{31,278}$ To this end, the patch-clamp technique has been used to detect the effect of organic films to neurons. Whole-cell patch-clamp techniques could evoke whole-cell currents and record current amplitude, while single-cell patch-clamp techniques could accurately characterize the effect of photostimulation on membrane potential. ${ }^{182}$ The transparent organic cell-stimulating/ sensing transistors (O-CST)/patch-clamp has been demonstrated to allow both extracellular current recording and optical read-out of membrane potential modulation. ${ }^{279}$

Action potentials of astrocyte membrane and primary neurons have been recorded in real time through patchclamp experiments on thin films of poly(3-hexylthiophene)
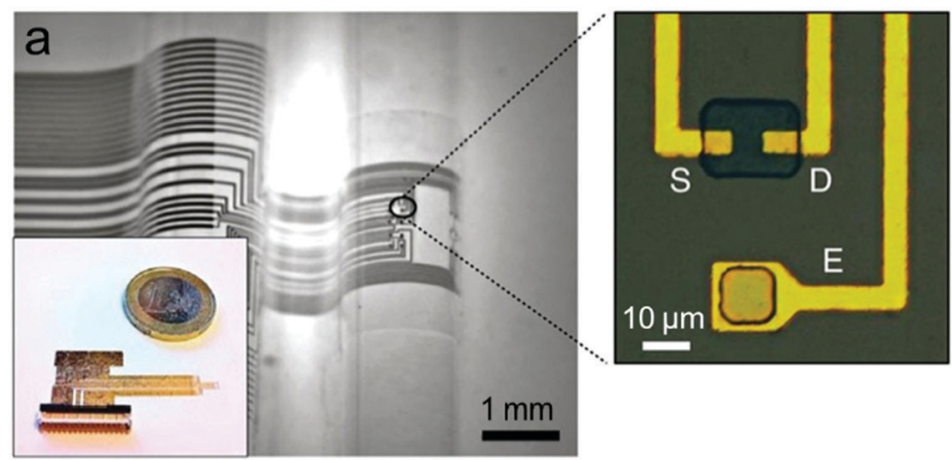

b

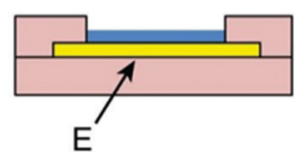

C

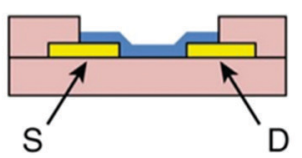

- Parylene $(2 \mu \mathrm{m})$

- Au $(100 \mathrm{~nm})$

- PEDOT:PSS $(200 \mathrm{~nm})$
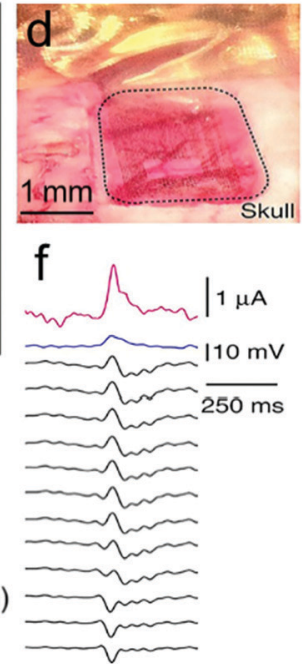

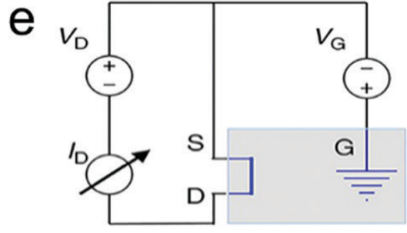

g

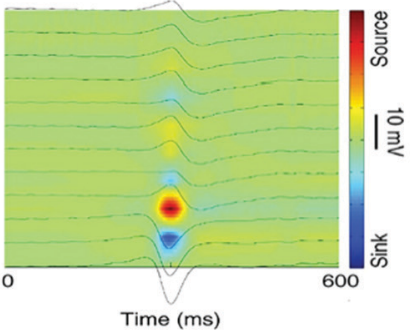

Fig. 16 Working principle and structure of OECT-based ECoG probes. (a) Optical micrograph of the probe conforming onto a curvilinear surface (left). Optical micrograph of the channel of a transistor and a surface electrode (right). (b) Layout of the surface electrode. (c) Layout of the transistor channel. (d) Optical micrograph of the ECoG probe placed over the somatosensory cortex, with the craniotomy surrounded by dashed lines. (e) Wiring layout of the transistor, with the blue box indicating the brain of the animal. (f) Recording of a bicuculline-induced epileptiform spike from a transistor (pink), a PEDOT:PSS surface electrode (blue) and 12 of the $16 \mathrm{Ir}$-penetrating electrodes (black). (g) Current source density map of a bicuculline-induced epileptiform spike. ${ }^{269}$ 


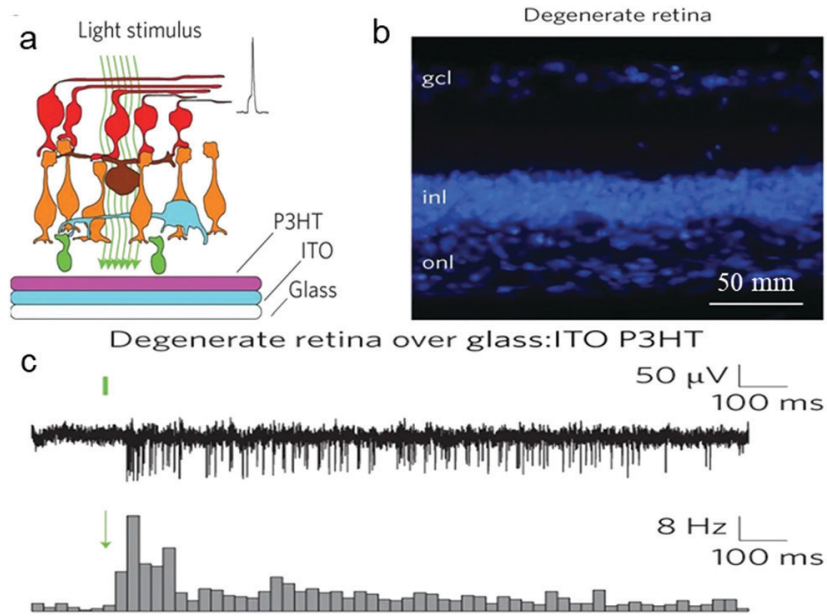

Fig. 17 Photovoltaic excitation of neurons mediated by a P3HT active layer. (a) Schematic illustration of the stimulation/recording interface for degenerate retinas. (b) Confocal images of latero-dorsal degenerate retinal sections labelled with the nuclear stain bisbenzimide (gcl, ganglion cell layer; inl, inner nuclear layer; onl, outer nuclear layer). (c) Top row: MUAs recorded with light stimulation (10 $\mathrm{ms}, 4 \mathrm{~mW} \mathrm{~mm}^{-2}$ ) of a degenerate retina over a P3HT-coated glass:ITO substrate. Bottom row: normalized poststimulus time histograms (PSTHs; bin, $25 \mathrm{~ms}$ ) computed based on all sweeps recorded in single retinas $\left(10 \mathrm{~ms}, 4 \mathrm{~mW} \mathrm{~mm}^{-2}\right)$ for the experimental conditions. Green bars/arrows represent the light stimulus. ${ }^{181}$

and phenyl- $\mathrm{C}_{61}$-butyric-acid-methyl ester (P3HT:PCBM) $)^{98,182,227}$ bulk heterojunctions under light irradiation. Ghezzi et al. recorded an active film only composed of the donor component, P3HT, to trigger neuronal firing upon illumination. ${ }^{181,280}$ Degenerated retinas were cultured on P3HT-coated glass/ITO under light irradiation (Fig. 17a and b). The output response of the retina to light showed that photostimulation cannot induce spiking activity in degenerated retinas on glass/ITO, but elicited intense activity in control retina on glass/ITO and degenerated retina on glass/ITO/P3HT. Meanwhile, the light-induced spiking activity of the latter two was similar to each other (Fig. 17c). These data showed that the donor component poly(3-hexylthiophene) (P3HT) under photostimulation has the potential to restore the light sensitivity of degenerated retina.

\section{Perspectives and challenges}

Neural tissue engineering as an emerging research field integrates neuronal cells, biomaterial scaffolds and bioactive factors into a biocompatible construct. A wide range of innovative functional organic polymers, advanced techniques and detection methods are being utilized to stimulate neural repair and regeneration. Various polymers provide an exciting option to fabricate customizable neural scaffolds with biocompatible architectures. In the future, it can be expected that more innovative polymer materials will be developed further for nanoscale manipulation of neuron behavior, and in turn create more biomimetic, biocompatible and stimuli-responsive (or adaptable) scaffolds for neural regeneration. For example, the development of conductive, ultraflexible and biodegradable polymer materials could be utilized as the injectable electronics for minimally invasive implantation and show high performance in chronic recording, neural monitoring, and single-neuron-level brain mapping. Moreover, tailor-made organic polymer scaffolds will enable strategies to develop multifunctional composites integrating biosensors, neural prostheses, tissue engineering and drug delivery. In addition, modern polymer-based microrobots with tunable power and speed, precise navigation and operation in biological media could provide new opportunities in neural repair and regeneration. ${ }^{281,282}$ These emerging capabilities of polymer materials and engineering techniques offer diverse biomedical opportunities for neural engineering in the future. ${ }^{283}$

Despite advances in both polymeric materials and techniques in neural tissue engineering, many challenges still exist. The complexity of the neural system makes successful clinical neural repair and regeneration still challenging. The main issues include the design of biomimetic scaffolds that can exhibit good biocompatibility, suitable conductivity and mechanical property, excellent host-implant integration and desirable biodegradability. To achieve the goal of stable neuronal stimulation and recording, special attention needs to be paid to robust and biocompatible functional organic polymers and interface-engineering techniques to manipulate the signal transduction at the biotic/abiotic interfaces. The new development in polymer/neuron interfacial engineering plays an increasingly important role in neurological rehabilitation and brain-machine interfaces that have shown promise for the restoration of limb mobility in paralyzed patients. ${ }^{284}$

\section{Summary}

The present review summarizes the recent advances of functional polymers for neural tissue engineering. We explored from how functional organic polymers guide cell behaviors and regeneration to the development of neural-response detectors for detecting neurophysiological activities, and highlighted several emerging applications of a polymer scaffold design. The method of fabrication plays a crucial role in determining polymer/neuron interface characteristics such as surface topography or chemical cues, macro/nanostructure, and other properties such as electrical conductivity or mechanical actuation that direct specific cell responses and induce formation of natural tissue. Based on the advantages of good biocompatibility, tunable conductivity, facile synthesis, and simple modification, polymer scaffolds demonstrate their potential in neuro regenerative medicine. Thanks to the rapid development of polymer design and fabrication, novel functional polymer/neuron interfaces have achieved improved tissue responses. Further investigation on the biocompatibility and long-term effects of new polymeric scaffolds would contribute to the development of safe neural prostheses for advanced applications such as brain-machine interfacing.

\section{Conflicts of interest}

There are no conflicts to declare. 


\section{Acknowledgements}

M.W. thanks the financial support by AcRF Tier 1 (Grant ID 2018-T1-001-173) from the Ministry of Education, Singapore. Y. W. thanks financial support by the National Natural Science Foundation of China (Grant No. 21802028).

\section{References}

1 M. M. Stevens and J. H. George, Exploring and engineering the cell surface interface, Science, 2005, 310, 1135-1138.

2 G. A. Saracino, D. Cigognini, D. Silva, A. Caprini and F. Gelain, Nanomaterials design and tests for neural tissue engineering, Chem. Soc. Rev., 2013, 42, 225-262.

3 D. E. Discher, D. J. Mooney and P. W. Zandstra, Growth factors, matrices, and forces combine and control stem cells, Science, 2009, 324, 1673-1677.

4 M. Wang, G. Mi, D. Shi, N. Bassous, D. Hickey and T. J. Webster, Nanotechnology and nanomaterials for improving neural interfaces, Adv. Funct. Mater., 2018, 28, 1700905.

5 M. R. Abidian and D. C. Martin, Multifunctional nanobiomaterials for neural interfaces, Adv. Funct. Mater., 2009, 19, 573-585.

6 M. Marcus, K. Baranes, M. Park, I. S. Choi, K. Kang and O. Shefi, Interactions of neurons with physical environments, Adv. Healthcare Mater., 2017, 6, 1700267.

7 D. Hoffman-Kim, J. A. Mitchel and R. V. Bellamkonda, Topography, cell response, and nerve regeneration, Annu. Rev. Biomed. Eng., 2010, 12, 203-231.

8 A. L. Carlson, N. K. Bennett, N. L. Francis, A. Halikere, S. Clarke, J. C. Moore, R. P. Hart, K. Paradiso, M. Wernig and J. Kohn, Generation and transplantation of reprogrammed human neurons in the brain using 3D microtopographic scaffolds, Nat. Commun., 2016, 7, 10862.

9 R. Boni, A. Ali, A. Shavandi and A. N. Clarkson, Current and novel polymeric biomaterials for neural tissue engineering, J. Biomed. Sci., 2018, 25, 90.

10 N. A. Kotov, J. O. Winter, I. P. Clements, E. Jan, B. P. Timko, S. Campidelli, S. Pathak, A. Mazzatenta, C. M. Lieber and M. Prato, Nanomaterials for neural interfaces, Adv. Mater., 2009, 21, 3970-4004.

11 J. A. Fairfield, Nanostructured materials for neural electrical interfaces, Adv. Funct. Mater., 2018, 28, 1701145.

12 L. Ghasemi-Mobarakeh, M. P. Prabhakaran, M. Morshed, M. H. Nasr-Esfahani, H. Baharvand, S. Kiani, S. Al-Deyab and S. Ramakrishna, Application of conductive polymers, scaffolds and electrical stimulation for nerve tissue engineering, J. Tissue Eng. Regener. Med., 2011, 5, 17-35.

13 A. C. Pinho, A. C. Fonseca, A. C. Serra, J. D. Santos and J. F. Coelho, Peripheral nerve regeneration: current status and new strategies using polymeric materials, Adv. Healthcare Mater., 2016, 5, 2732-2744.

14 A. D. Mickle, S. M. Won, K. N. Noh, J. Yoon, K. W. Meacham, Y. G. Xue, L. A. McIlvried, B. A. Copits, V. K. Samineni and K. E. Crawford, A wireless closed-loop system for optogenetic peripheral neuromodulation, Nature, 2019, 565, 361-365.

15 X. Navarro, T. B. Krueger, N. Lago, S. Micera, T. Stieglitz and P. Dario, A critical review of interfaces with the peripheral nervous system for the control of neuroprostheses and hybrid bionic systems, J. Peripher. Nerv. Syst., 2005, 10, 229-258.

16 B. M. Baker, B. Trappmann, W. Y. Wang, M. S. Sakar, I. L. Kim, V. B. Shenoy, J. A. Burdick and C. S. Chen, Cellmediated fibre recruitment drives extracellular matrix mechanosensing in engineered fibrillar microenvironments, Nat. Mater., 2015, 14, 1262.

17 C. M. Madl, S. C. Heilshorn and H. M. Blau, Bioengineering strategies to accelerate stem cell therapeutics, Nature, 2018, 557, 335-342.

18 L. G. Griffith and G. Naughton, Tissue engineering-current challenges and expanding opportunities, Science, 2002, 295, 1009-1014.

19 W. Zhu, C. O’Brien, J. R. O'Brien and L. G. Zhang, 3D nano/ microfabrication techniques and nanobiomaterials for neural tissue regeneration, Nanomedicine, 2014, 9, 859-875.

20 X. Gu, F. Ding and D. F. Williams, Neural tissue engineering options for peripheral nerve regeneration, Biomaterials, 2014, 35, 6143-6156.

21 H. Shin, S. Jo and A. G. Mikos, Biomimetic materials for tissue engineering, Biomaterials, 2003, 24, 4353-4364.

22 Z. Wei, O. B. Christopher, J. R. O'Brien and Z. J. N. Lijie Grace, 3D nano/microfabrication techniques and nanobiomaterials for neural tissue regeneration, Nanomedicine, 2014, 9, 859-875.

23 V. D. Ranjan, L. Qiu, E. K. Tan, L. Zeng and Y. Zhang, Modelling Alzheimer's disease: insights from in vivo to in vitro three-dimensional culture platforms, J. Tissue Eng. Regener. Med., 2018, 12, 1944-1958.

24 E. Sánchez-López, M. Ettcheto, M. A. Egea, M. Espina, A. Cano, A. C. Calpena, A. Camins, N. Carmona, A. M. Silva and E. B. Souto, Memantine loaded PLGA PEGylated nanoparticles for Alzheimer's disease: in vitro and in vivo characterization, J. Nanobiotechnol., 2018, 16, 32.

25 R. G. Canter, J. Penney and L.-H. Tsai, The road to restoring neural circuits for the treatment of Alzheimer's disease, Nature, 2016, 539, 187-196.

26 S. K. Seidlits, J. Y. Lee and C. E. Schmidt, Nanostructured scaffolds for neural applications, Nanomedicine, 2008, 3, 183-199.

27 A. Abeliovich and A. D. Gitler, Defects in trafficking bridge Parkinson's disease pathology and genetics, Nature, 2016, 539, 207-216.

28 T. Wichmann and M. R. DeLong, Deep brain stimulation for neurologic and neuropsychiatric disorders, Neuron, 2006, 52, 197-204.

29 N. Daviaud, E. Garbayo, P. C. Schiller, M. Perez-Pinzon and C. N. Montero-Menei, Organotypic cultures as tools for optimizing central nervous system cell therapies, Exp. Neurol., 2013, 248, 429-440.

30 T. Wyss-Coray, Ageing, neurodegeneration and brain rejuvenation, Nature, 2016, 539, 180-186. 
31 S. Park, G. Loke, Y. Fink and P. Anikeeva, Flexible fiberbased optoelectronics for neural interfaces, Chem. Soc. Rev., 2019, 48, 1826-1852.

32 R. Mohammadinejad, A. Kumar, M. Ranjbar-Mohammadi, M. Ashrafizadeh, S. S. Han, G. Khang and Z. Roveimiab, Recent advances in natural gum-based biomaterials for tissue engineering and regenerative medicine: A review, Polymer, 2020, 12, 176.

33 A. Subramanian, U. M. Krishnan and S. Sethuraman, Development of biomaterial scaffold for nerve tissue engineering: Biomaterial mediated neural regeneration, J. Biomed. Sci., 2009, 16, 108.

34 E. Lavik and R. Langer, Tissue engineering: current state and perspectives, Appl. Microbiol. Biotechnol., 2004, 65, 1-8.

35 P. Sensharma, G. Madhumathi, R. D. Jayant and A. K. Jaiswal, Biomaterials and cells for neural tissue engineering: Current choices, Mater. Sci. Eng., C, 2017, 77, 1302-1315.

36 C. J. Dong and Y. G. Lv, Application of collagen scaffold in tissue engineering: recent advances and new perspectives, Polymer, 2016, 8, 42.

37 J. P. Jiang, X. Y. Liu, F. Zhao, X. Zhu, X. Y. Li, X. G. Niu, Z. T. Yao, C. Dai, H. Y. Xu and K. Ma, Three-dimensional bioprinting collagen/silk fibroin scaffold combined with neural stem cells promotes nerve regeneration after spinal cord injury, Neural Regener. Res., 2020, 15, 959.

38 M. Farokhi, F. Mottaghitalab, M. A. Shokrgozar, D. L. Kaplan, H.-W. Kim and S. C. Kundu, Prospects of peripheral nerve tissue engineering using nerve guide conduits based on silk fibroin protein and other biopolymers, Int. Mater. Rev., 2017, 62, 367-391.

39 B. Kundu, R. Rajkhowa, S. C. Kundu and X. Wang, Silk fibroin biomaterials for tissue regenerations, Adv. Drug Delivery Rev., 2013, 65, 457-470.

40 A. Raspa, A. Marchini, R. Pugliese, M. Mauri, M. Maleki, R. Vasita and F. Gelain, A biocompatibility study of new nanofibrous scaffolds for nervous system regeneration, Nanoscale, 2016, 8, 253-265.

41 R. Alizadeh, P. Zarrintaj, S. K. Kamrava, Z. Bagher, M. Farhadi, F. Heidari, A. Komeili, T. J. Gutiérrez and M. R. Saeb, Conductive hydrogels based on agarose/alginate/chitosan for neural disorder therapy, Carbohydr. Polym., 2019, 224, 115161.

42 R. Kleene and M. Schachner, Glycans and neural cell interactions, Nat. Rev. Neurosci., 2004, 5, 195-208.

43 X. M. Wang, J. He, Y. Wang and F. Z. Cui, Hyaluronic acidbased scaffold for central neural tissue engineering, Interface Focus, 2012, 2, 278-291.

44 A. Pinho, M. E. V. Branquinho, R. Alvites, A. C. Fonseca, A. Caseiro, S. S. Pedrosa, A. Luís, I. Pires, J. Prada and L. Muratori, Dextran-based tube-guides for the regeneration of the rat sciatic nerve after neurotmesis injury, Biomater. Sci., 2020, 8, 798-811.

45 A. Böcker, S. C. Daeschler, U. Kneser and L. Harhaus, Relevance and recent developments of chitosan in peripheral nerve surgery, Front. Cell. Neurosci., 2019, 13, 104.

46 L. Gan, L. Zhao, Y. Zhao, K. Li, Z. Tong, L. Yi, X. Wang, Y. Li, $\mathrm{W}$. Tian and X. He, Cellulose/soy protein composite-based nerve guidance conduits with designed microstructure for peripheral nerve regeneration, J. Neural Eng., 2016, 13, 056019.

47 M. N. Collins and C. Birkinshaw, Hyaluronic acid based scaffolds for tissue engineering-A review, Carbohydr. Polym., 2013, 92, 1262-1279.

48 P. Rastogi and B. Kandasubramanian, Review of alginatebased hydrogel bioprinting for application in tissue engineering, Biofabrication, 2019, 11, 042001.

49 T. Freier, H. S. Koh, K. Kazazian and M. S. Shoichet, Controlling cell adhesion and degradation of chitosan films by N-acetylation, Biomaterials, 2005, 26, 5872-5878.

50 C. Meyer, L. Stenberg, F. Gonzalez-Perez, S. Wrobel, G. Ronchi, E. Udina, S. Suganuma, S. Geuna, X. Navarro and L. B. Dahlin, Chitosan-film enhanced chitosan nerve guides for long-distance regeneration of peripheral nerves, Biomaterials, 2016, 76, 33-51.

51 S. Wang, S. Guan, J. Wang, H. Liu, T. Liu, X. Ma and Z. Cui, Fabrication and characterization of conductive poly $(3,4-$ ethylenedioxythiophene) doped with hyaluronic acid/poly (L-lactic acid) composite film for biomedical application, J. Biosci. Bioeng., 2017, 123, 116-125.

52 S. M. Wellman, J. R. Eles, K. A. Ludwig, J. P. Seymour, N. J. Michelson, W. E. McFadden, A. L. Vazquez and T. D. Kozai, A materials roadmap to functional neural interface design, Adv. Funct. Mater., 2018, 28, 1701269.

53 H. Zhang, W. H. Pei, S. S. Zhao, X. W. Yang, R. C. Liu, Y. Y. Liu, X. Wu, D. M. Guo, Q. Gui and X. H. Guo, Fabrication of iridium oxide neural electrodes at the wafer level, Sci. China: Technol. Sci., 2016, 59, 1399-1406.

54 M. Lichtenstein, E. Pérez, L. Ballesteros, C. Suñol and N. Casañ-Pastor, Short-term electrostimulation enhancing neural repair in vitro using large charge capacity nanostructured electrodes, Appl. Mater. Today, 2017, 6, 29-43.

55 S. Schlie-Wolter, A. Deiwick, E. Fadeeva, G. Paasche, T. Lenarz and B. Chichkov, Topography and coating of platinum improve the electrochemical properties and neuronal guidance, ACS Appl. Mater. Interfaces, 2013, 5, 1070-1077.

56 P. Fattahi, G. Yang, G. Kim and M. R. Abidian, A review of organic and inorganic biomaterials for neural interfaces, Adv. Mater., 2014, 26, 1846-1885.

57 G. Bonaventura, R. Iemmolo, V. La Cognata, M. Zimbone, F. La Via, M. E. Fragalà, M. L. Barcellona, R. Pellitteri and S. Cavallaro, Biocompatibility between silicon or silicon carbide surface and neural stem cells, Sci. Rep., 2019, 9, 1-13.

58 R. Dell'Anna, C. Masciullo, E. Iacob, M. Barozzi, D. Giubertoni, R. Böttger, M. Cecchini and G. Pepponi, Multiscale structured germanium nanoripples as templates for bioactive surfaces, RSC Adv., 2017, 7, 9024-9030.

59 P. J. Snyder, P. Reddy, R. Kirste, D. R. LaJeunesse, R. Collazo and A. Ivanisevic, Noninvasive stimulation of neurotypic cells using persistent photoconductivity of gallium nitride, ACS Omega, 2018, 3, 615-621.

60 K. Baranes, M. Shevach, O. Shefi and T. Dvir, Gold nanoparticle-decorated scaffolds promote neuronal differentiation and maturation, Nano Lett., 2016, 16, 2916-2920. 
61 M. A. Colicos, B. E. Collins, M. J. Sailor and Y. Goda, Remodeling of synaptic actin induced by photoconductive stimulation, Cell, 2001, 107, 605-616.

62 R. Green and M. R. Abidian, Conducting polymers for neural prosthetic and neural interface applications, $A d v$. Mater., 2015, 27, 7620-7637.

63 Y. Qian, X. Zhao, Q. Han, W. Chen, H. Li and W. Yuan, An integrated multi-layer 3D-fabrication of PDA/RGD coated graphene loaded PCL nanoscaffold for peripheral nerve restoration, Nat. Commun., 2018, 9, 1-16.

64 X. Liu, A. L. Miller, S. Park, B. E. Waletzki, Z. Zhou, A. Terzic and L. Lu, Interfaces, Functionalized carbon nanotube and graphene oxide embedded electrically conductive hydrogel synergistically stimulates nerve cell differentiation, ACS Appl. Mater. Interfaces, 2017, 9, 14677-14690.

65 S. Kumar and K. Chatterjee, Comprehensive review on the use of graphene-based substrates for regenerative medicine and biomedical devices, ACS Appl. Mater. Interfaces, 2016, 8, 26431-26457.

66 T. J. Webster, M. C. Waid, J. L. McKenzie, R. L. Price and J. U. Ejiofor, Nano-biotechnology: carbon nanofibres as improved neural and orthopaedic implants, Nanotechnology, 2003, 15, 48.

67 W. Guo, X. Zhang, X. Yu, S. Wang, J. Qiu, W. Tang, L. Li, H. Liu and Z. L. Wang, Self-powered electrical stimulation for enhancing neural differentiation of mesenchymal stem cells on graphene-poly(3,4-ethylenedioxythiophene) hybrid microfibers, ACS Nano, 2016, 10, 5086-5095.

68 X. L. Chen, Y. J. Wu, V. D. Ranjan and Y. L. Zhang, Threedimensional electrical conductive scaffold from biomaterial-based carbon microfiber sponge with bioinspired coating for cell proliferation and differentiation, Carbon, 2018, 134, 174-182.

69 S. J. Lee, W. Zhu, M. Nowicki, G. Lee, D. N. Heo, J. Kim, Y. Y. Zuo and L. G. Zhang, 3D printing nano conductive multi-walled carbon nanotube scaffolds for nerve regeneration, J. Neural Eng., 2018, 15, 016018.

70 W. Zhu, T. Ye, S.-J. Lee, H. Cui, S. D. Miao, X. Zhou, D. M. Shuai and L. G. Zhang, Enhanced neural stem cell functions in conductive annealed carbon nanofibrous scaffolds with electrical stimulation, Nanomedicine, 2018, 14, 2485-2494.

71 J. Y. Hwang, U. S. Shin, W. C. Jang, J. K. Hyun, I. B. Wall and $\mathrm{H}$. W. Kim, Biofunctionalized carbon nanotubes in neural regeneration: a mini-review, Nanoscale, 2013, 5, 487-497.

72 J. Chen, M. Yu, B. Guo, P. X. Ma and Z. Yin, Conductive nanofibrous composite scaffolds based on in-situ formed polyaniline nanoparticle and polylactide for bone regeneration, J. Colloid Interface Sci., 2018, 514, 517-527.

73 J. J. Norman and T. A. Desai, Methods for fabrication of nanoscale topography for tissue engineering scaffolds, Ann. Biomed. Eng., 2006, 34, 89-101.

74 S.-J. Lee, M. Nowicki, B. Harris and L. G. Zhang, Fabrication of a highly aligned neural scaffold via a table top stereolithography 3D printing and electrospinning, Tissue Eng., Part A, 2017, 23, 491-502.

75 S. Miao, H. Cui, M. Nowicki, L. Xia, X. Zhou, S. J. Lee, W. Zhu, K. Sarkar, Z. Zhang and L. G. Zhang, Stereolithographic 4D bioprinting of multiresponsive architectures for neural engineering, Adv. Biosyst., 2018, 2, 1800101.

76 G. Zhang, Z. Y. Zhao and D. Y. Wang, Colloidal lithography- construction and application of nanostructured surfaces, Chem. J. Chin. Univ., 2010, 31, 839-854.

77 S. W. Myung, Y. M. Ko and B. H. Kim, Protein adsorption and cell adhesion on three-dimensional polycaprolactone scaffolds with respect to plasma modification by etching and deposition techniques, Jpn. J. Appl. Phys., 2014, 53, $11 \mathrm{~s}$.

78 Y. J. Wu, Y. F. Peng, H. Bohra, J. P. Zou, V. D. Ranjan, Y. L. Zhang, Q. Zhang and M. F. Wang, Photoconductive micro/nanoscale interfaces of a semiconducting polymer for wireless stimulation of neuron-like cells, ACS Appl. Mater. Interfaces, 2019, 11, 4833-4841.

79 L. Min, J. C. Y. Dunn and B. M. Wu, Scaffold fabrication by indirect three-dimensional printing, Biomaterials, 2005, 26, 4281-4289.

80 W. Aljohani, M. W. Ullah, X. Zhang and G. Yang, Bioprinting and its applications in tissue engineering and regenerative medicine, Int. J. Biol. Macromol., 2018, 107, 261-275.

81 S. J. Lee, T. Esworthy, S. Stake, S. Miao, Y. Y. Zuo, B. T. Harris and L. G. Zhang, Advances in 3D bioprinting for neural tissue engineering, Adv. Biosyst., 2018, 2, 1700213.

82 Q. Gu, E. Tomaskovic-Crook, R. Lozano, Y. Chen, R. M. Kapsa, Q. Zhou, G. G. Wallace and J. M. Crook, Functional 3D neural mini-tissues from printed gel-based bioink and human neural stem cells, Adv. Healthcare Mater., 2016, 5, 1429-1438.

83 S. C. Zhang, M. Xing and B. Y. Li, Biomimetic layer-by-layer self-assembly of nanofilms, nanocoatings, and 3D scaffolds for tissue engineering, Int. J. Mol. Sci., 2018, 19, 1641.

84 P. Bajaj, R. M. Schweller, A. Khademhosseini, J. L. West and R. Bashir, 3D biofabrication strategies for tissue engineering and regenerative medicine, Annu. Rev. Biomed. Eng., 2014, 16, 247-276.

85 S. Snigdha, T. Sabu and E. Radhakrishnan, Polymer based tissue engineering strategies for neural regeneration, $A d v$. Tissue Eng. Regen. Med., 2017, 2, 1-6.

86 A. Cobo, C. Larson, K. Scholten, J. A. Miranda, S. Elyahoodayan, D. Song, V. Pikov and E. Meng, Parylene-based cuff electrode with integrated microfluidics for peripheral nerve recording, stimulation, and drug delivery, J. Microelectromech. Syst., 2019, 28, 36-49.

87 S. Biswas, D. Sikdar, D. Das, M. Mahadevappa and S. Das, PDMS based multielectrode arrays for superior in-vitro retinal stimulation and recording, Biomed. Microdevices, 2017, 19, 1-14.

88 B. Ji, Z. Guo, M. Wang, B. Yang, X. Wang, W. Li and J. Liu, Flexible polyimide-based hybrid opto-electric neural 
interface with 16 channels of micro-LEDs and electrodes, Microsyst. Nanoeng., 2018, 4, 27.

89 Y. Zhao, C. Niu, J. Shi, Y. Wang, Y. Yang and H. Wang, Novel conductive polypyrrole/silk fibroin scaffold for neural tissue repair, Neural Regener. Res., 2018, 13, 1455.

90 J. J. D. Ouyang, "Secondary doping” methods to significantly enhance the conductivity of PEDOT:PSS for its application as transparent electrode of optoelectronic devices, Displays, 2013, 34, 423-436.

91 J. Huang, P. F. Miller, J. C. De Mello, A. J. De Mello and D. D. C. Bradley, Influence of thermal treatment on the conductivity and morphology of PEDOT/PSS films, Synth. Met., 2003, 139, 569-572.

92 S. Jonsson, J. Birgerson, X. Crispin, G. Greczynski, W. Osikowicz, A. W. D. V. Der Gon, W. R. Salaneck and M. Fahlman, The effects of solvents on the morphology and sheet resistance in poly(3,4-ethylenedioxythiophene)polystyrenesulfonic acid (PEDOT-PSS) films, Synth. Met., 2003, 139, 1-10.

93 T. Wang, Y. Qi, J. Xu, X. Hu and P. Chen, Effects of poly(ethylene glycol) on electrical conductivity of poly(3,4ethylenedioxythiophene)-poly(styrenesulfonic acid) film, Appl. Surf. Sci., 2005, 250, 188-194.

94 D. T. Simon, E. O. Gabrielsson, K. Tybrandt and M. Berggren, Organic bioelectronics: bridging the signaling gap between biology and technology, Chem. Rev., 2016, 116, 13009-13041.

95 E. Zeglio, A. L. Rutz, T. E. Winkler, G. G. Malliaras and A. Herland, Conjugated polymers for assessing and controlling biological functions, Adv. Mater., 2019, 31, 1806712.

96 V. Mahairaki, S. H. Lim, G. T. Christopherson, L. Xu, I. Nasonkin, C. Yu, H. Q. Mao and V. E. Koliatsos, Nanofiber matrices promote the neuronal differentiation of human embryonic stem cell-derived neural precursors in vitro, Tissue Eng., Part A, 2011, 17, 855-863.

97 H. J. Diao, K. Wang, H. Y. Long, M. Wang and S. Y. Chew, Highly fluorescent and photostable polymeric nanofibers as scaffolds for cell interfacing and long-term tracking, Adv. Healthcare Mater., 2016, 5, 529-533.

98 H. Yamamoto, R. Matsumura, H. Takaoki, S. Katsurabayashi, A. Hirano-Iwata and M. Niwano, Unidirectional signal propagation in primary neurons micropatterned at a single-cell resolution, Appl. Phys. Lett., 2016, 109, 043703.

99 R. A. Koppes, S. Park, T. Hood, X. Jia, N. A. Poorheravi, A. H. Achyuta, Y. Fink and P. Anikeeva, Thermally drawn fibers as nerve guidance scaffolds, Biomaterials, 2016, 81, 27-35.

100 G. T. Christopherson, H. Song and H.-Q. Mao, The influence of fiber diameter of electrospun substrates on neural stem cell differentiation and proliferation, Biomaterials, 2009, 30, 556-564.

101 Z. Yin, X. Chen, J. L. Chen, W. L. Shen, T. M. H. Nguyen, L. Gao and H. W. Ouyang, The regulation of tendon stem cell differentiation by the alignment of nanofibers, Biomaterials, 2010, 31, 2163-2175.

102 S. J. Lee, M. Heo, D. Lee, D. N. Heo, H.-N. Lim and I. K. Kwon, Fabrication and design of bioactive agent coated, highly-aligned electrospun matrices for nerve tissue engineering: Preparation, characterization and application, Appl. Surf. Sci., 2017, 424, 359-367.

103 F. Yang, R. Murugan, S. Wang and S. Ramakrishna, Electrospinning of nano/micro scale poly (L-lactic acid) aligned fibers and their potential in neural tissue engineering, Biomaterials, 2005, 26, 2603-2610.

104 X. Li, M. Li, J. Sun, Y. Zhuang, J. Shi, D. Guan, Y. Chen and J. Dai, Radially aligned electrospun fibers with continuous gradient of SDF1 $\alpha$ for the guidance of neural stem cells, Small, 2016, 12, 5009-5018.

105 C. M. Kofron and D. J. C. Hoffman-Kim, Bioengineering, Optimization by response surface methodology of confluent and aligned cellular monolayers for nerve guidance, Cell. Mol. Bioeng., 2009, 2, 554.

106 L. Grace Ngayin and H. K. Diane, Evaluation of neurite outgrowth anisotropy using a novel application of circular analysis, J. Neurosci. Methods, 2008, 174, 202-214.

107 F. Johansson, P. Carlberg, N. Danielsen, L. Montelius and M. J. B. Kanje, Axonal outgrowth on nano-imprinted patterns, Biomaterials, 2006, 27, 1251-1258.

108 J. J. Xue, T. Wu, Y. Q. Dai and Y. N. Xia, Electrospinning and electrospun nanofibers: Methods, materials, and applications, Chem. Rev., 2019, 119, 5298-5415.

109 Y.-t. Kim, V. K. Haftel, S. Kumar and R. V. Bellamkonda, The role of aligned polymer fiber-based constructs in the bridging of long peripheral nerve gaps, Biomaterials, 2008, 29, 3117-3127.

110 S. Nagam Hanumantharao and S. Rao, Multi-functional electrospun nanofibers from polymer blends for scaffold tissue engineering, Fibers, 2019, 7, 66.

111 E. Soliman, F. Bianchi, J. N. Sleigh, J. H. George, M. Z. Cader, Z. Cui and H. Ye, Aligned electrospun fibers for neural patterning, Biotechnol. Lett., 2018, 40, 601-607.

112 J. M. Corey, D. Y. Lin, K. B. Mycek, Q. Chen, S. Samuel, E. L. Feldman and D. C. Martin, Aligned electrospun nanofibers specify the direction of dorsal root ganglia neurite growth, J. Biomed. Mater. Res., Part A, 2007, 83, 636-645.

113 J. M. Jang, S. H. Tran, S. C. Na and N. L. Jeon, Engineering controllable architecture in matrigel for $3 \mathrm{D}$ cell alignment, ACS Appl. Mater. Interfaces, 2015, 7, 2183-2188.

114 L. Wang, Y. B. Wu, B. L. Guo and P. X. Ma, Nanofiber yarn/ hydrogel core-shell scaffolds mimicking native skeletal muscle tissue for guiding 3D myoblast alignment, elongation, and differentiation, ACS Nano, 2015, 9, 9167-9179.

115 J. N. Hanson Shepherd, S. T. Parker, R. F. Shepherd, M. U. Gillette, J. A. Lewis and R. G. Nuzzo, 3D microperiodic hydrogel scaffolds for robust neuronal cultures, Adv. Funct. Mater., 2011, 21, 47-54.

116 M. R. Hynd, J. P. Frampton, N. Dowell-Mesfin, J. N. Turner and W. Shain, Directed cell growth on proteinfunctionalized hydrogel surfaces, J. Neurosci. Methods, 2007, 162, 255-263.

117 N. Mauro, A. Manfredi, E. Ranucci, P. Procacci, M. Laus, D. Antonioli, C. Mantovani, V. Magnaghi and P. Ferruti, 
Degradable poly(amidoamine) hydrogels as scaffolds for in vitro culturing of peripheral nervous system cells, Macromol. Biosci., 2013, 13, 332-347.

118 H. Yuk, B. Y. Lu and X. H. Zhao, Hydrogel bioelectronics, Chem. Soc. Rev., 2019, 48, 1642-1667.

119 Z. Zhou, P. Yu, H. M. Geller and C. K. Ober, Biomimetic polymer brushes containing tethered acetylcholine analogs for protein and hippocampal neuronal cell patterning, Biomacromolecules, 2013, 14, 529-537.

120 K. Chwalek, Y. Dening, C. Hinuber, H. Brunig, M. Nitschke and C. Werner, Providing the right cues in nerve guidance conduits: Biofunctionalization versus fiber profile to facilitate oriented neuronal outgrowth, Mater. Sci. Eng., C, 2016, 61, 466-472.

121 C. Hinuber, K. Chwalek, F. J. Pan-Montojo, M. Nitschke, R. Vogel, H. Brunig, G. Heinrich and C. Werner, Hierarchically structured nerve guidance channels based on poly-3hydroxybutyrate enhance oriented axonal outgrowth, Acta Biomater., 2014, 10, 2086-2095.

122 R. Barille, R. Janik, S. Kucharski, J. Eyer and F. Letournel, Photo-responsive polymer with erasable and reconfigurable micro- and nano-patterns: an in vitro study for neuron guidance, Colloids Surf., B, 2011, 88, 63-71.

123 C. J. Bettinger, B. Orrick, A. Misra, R. Langer and J. T. Borenstein, Microfabrication of poly (glycerol-sebacate) for contact guidance applications, Biomaterials, 2006, 27, 2558-2565.

$124 \mathrm{~J} . \mathrm{Li}, \mathrm{H}$. McNally and R. Shi, Enhanced neurite alignment on micro-patterned poly-L-lactic acid films, J. Biomed. Mater. Res., Part A, 2008, 87, 392-404.

125 A. M. McCormick, M. V. Maddipatla, S. Shi, E. A. Chamsaz, H. Yokoyama, A. Joy and N. D. Leipzig, Micropatterned coumarin polyester thin films direct neurite orientation, ACS Appl. Mater. Interfaces, 2014, 6, 19655-19667.

126 L. Vaysse, A. Beduer, J. C. Sol, C. Vieu and I. Loubinoux, Micropatterned bioimplant with guided neuronal cells to promote tissue reconstruction and improve functional recovery after primary motor cortex insult, Biomaterials, 2015, 58, 46-53.

127 L. Yao, S. Wang, W. Cui, R. Sherlock, C. O'Connell, G. Damodaran, A. Gorman, A. Windebank and A. Pandit, Effect of functionalized micropatterned PLGA on guided neurite growth, Acta Biomater., 2009, 5, 580-588.

128 Q. Huang, Y. Zou, M. C. Arno, S. Chen, T. Wang, J. Gao, A. P. Dove and J. Z. Du, Hydrogel scaffolds for differentiation of adipose-derived stem cells, Chem. Soc. Rev., 2017, 46, 6255-6275.

129 R. Singhvi, A. Kumar, G. P. Lopez, G. N. Stephanopoulos, D. I. Wang, G. M. Whitesides and D. E. Ingber, Engineering cell shape and function, Science, 1994, 264, 696-698.

130 Y. Wu, V. D. Ranjan and Y. Zhang, A living 3D in vitro neuronal network cultured inside hollow electrospun microfibers, Adv. Biosyst., 2018, 2, 1700218.

131 D. Shahriari, G. Loke, I. Tafel, S. Park, P. H. Chiang, Y. Fink and P. Anikeeva, Scalable fabrication of porous microchannel nerve guidance scaffolds with complex geometries, Adv. Mater., 2019, 31, 1902021.
132 Y. Hu, J. O. You and J. Aizenberg, Micropatterned hydrogel surface with high-aspect-ratio features for cell guidance and tissue growth, ACS Appl. Mater. Interfaces, 2016, 8, 21939-21945.

133 S. B. Yu, J. Baek, M. Choi, Y. Oh, H. R. Lee, S. J. Yu, E. Lee, J. W. Sohn, S. G. Im and S. Jon, Polymer thin films with tunable acetylcholine-like functionality enable long-term culture of primary hippocampal neurons, ACS Nano, 2016, 10, 9909-9918.

134 S. H. Bhang, Lee. Tae-Jin, H. S. Yang, W.-G. La, A. M. Han, Y. H. K. Kwon and B.-S. Kim, Enhanced nerve growth factor efficiency in neural cell culture by immobilization on the culture substrate, Biochem. Biophys. Res. Commun., 2009, 382, 315-320.

135 H. Koh, T. Yong, C. Chan and S. Ramakrishna, Enhancement of neurite outgrowth using nano-structured scaffolds coupled with laminin, Biomaterials, 2008, 29, 3574-3582.

136 K. Yang, J. S. Lee, J. Kim, Y. B. Lee, H. Shin, S. H. Um, J. B. Kim, K. I. Park, H. Lee and S.-W. Cho, Polydopaminemediated surface modification of scaffold materials for human neural stem cell engineering, Biomaterials, 2012, 33, 6952-6964.

137 J. Arulmoli, H. J. Wright, D. T. Phan, U. Sheth, R. A. Que, G. A. Botten, M. Keating, E. L. Botvinick, M. M. Pathak and T. I. Zarembinski, Combination scaffolds of salmon fibrin, hyaluronic acid, and laminin for human neural stem cell and vascular tissue engineering, Acta Biomater., 2016, 43, 122-138.

138 N. Chen, L. Tian, A. C. Patil, S. Peng, I. H. Yang, N. V. Thakor and S. Ramakrishna, Neural interfaces engineered via micro-and nanostructured coatings, Nano Today, 2017, 14, 59-83.

139 C.-W. Yeh, L.-W. Wang, H.-C. Wu, Y.-K. Hsieh, J. Wang, M.-H. Chen and T.-W. Wang, Development of biomimetic micro-patterned device incorporated with neurotrophic gradient and supportive Schwann cells for the applications in neural tissue engineering, Biofabrication, 2017, 9, 015024.

140 A. C. Lee, V. M. Yu, J. B. Lowe, M. J. Brenner, D. A. Hunter, S. E. Mackinnon and S. E. Sakiyama-Elbert, Controlled release of nerve growth factor enhances sciatic nerve regeneration, Exp. Neurol., 2003, 184, 295-303.

141 J. Sanchez-Ramos, S. Song, F. Cardozo-Pelaez, C. Hazzi, T. Stedeford, A. Willing, T. B. Freeman, S. Saporta, W. Janssen and N. Patel, Adult bone marrow stromal cells differentiate into neural cells in vitro, Exp. Neurol., 2000, 164, 247-256.

142 J. E. Babensee, L. V. McIntire and A. G. Mikos, Growth factor delivery for tissue engineering, Pharm. Res., 2000, 17, 497-504.

143 Y. I. Cho, J. S. Choi, S. Y. Jeong and H. S. Yoo, Nerve growth factor (NGF)-conjugated electrospun nanostructures with topographical cues for neuronal differentiation of mesenchymal stem cells, Acta Biomater., 2010, 6, 4725-4733.

144 J. Hu, L. Tian, M. P. Prabhakaran, X. Ding and S. Ramakrishna, Fabrication of nerve growth factor encapsulated aligned poly ( $\varepsilon$-caprolactone) nanofibers and their 
assessment as a potential neural tissue engineering scaffold, Polymer, 2016, 8, 54.

145 M. K. Horne, D. R. Nisbet, J. S. Forsythe and C. L. Parish, Three-dimensional nanofibrous scaffolds incorporating immobilized BDNF promote proliferation and differentiation of cortical neural stem cells, Stem Cells Dev., 2010, 19, 843-852.

146 K. E. Crompton, J. D. Goud, R. V. Bellamkonda, T. R. Gengenbach, D. I. Finkelstein, M. K. Horne and J. S. Forsythe, Polylysine-functionalised thermoresponsive chitosan hydrogel for neural tissue engineering, Biomaterials, 2007, 28, 441-449.

147 H. S. Koh, T. Yong, C. K. Chan and S. Ramakrishna, Enhancement of neurite outgrowth using nano-structured scaffolds coupled with laminin, Biomaterials, 2008, 29, 3574-3582.

148 S. Wang, E. Jeffries, J. Gao, L. Sun, Z. You and Y. Wang, Polyester with pendent acetylcholine-mimicking functionalities promotes neurite growth, ACS Appl. Mater. Interfaces, 2016, 8, 9590-9599.

149 D. Xing, L. Ma and C. Gao, Synthesis of poly(estercarbonate) with a pendant acetylcholine analog for promoting neurite growth, Acta Biomater., 2014, 10, 4127-4135.

150 R. H. Harrison, J. A. Steele, R. Chapman, A. J. Gormley, L. W. Chow, M. M. Mahat, L. Podhorska, R. G. Palgrave, D. J. Payne, S. P. Hettiaratchy, I. E. Dunlop and M. M. Stevens, Modular and versatile spatial functionalization of tissue engineering scaffolds through fiber-Initiated controlled radical polymerization, Adv. Funct. Mater., 2015, 25, 5748-5757.

151 D. E. Discher, P. Janmey and Y. L. Wang, Tissue cells feel and respond to the stiffness of their substrate, Science, 2005, 310, 1139-1143.

152 A. M. Kloxin, A. M. Kasko, C. N. Salinas and K. S. Anseth, Photodegradable hydrogels for dynamic tuning of physical and chemical properties, Science, 2009, 324, 59-63.

153 T. E. Brown and K. S. Anseth, Spatiotemporal hydrogel biomaterials for regenerative medicine, Chem. Soc. Rev., 2017, 46, 6532-6552.

154 Y. Segawa, H. Ito and K. Itami, Structurally uniform and atomically precise carbon nanostructures, Nat. Rev. Mater., 2016, 1, 1-14.

155 M. Shafiq, Y. Jung and S. H. Kim, Insight on stem cell preconditioning and instructive biomaterials to enhance cell adhesion, retention, and engraftment for tissue repair, Biomaterials, 2016, 90, 85-115.

156 A. Sadeghi, F. Moztarzadeh and J. A. Mohandesi, Investigating the effect of chitosan on hydrophilicity and bioactivity of conductive electrospun composite scaffold for neural tissue engineering, Int. J. Biol. Macromol., 2019, 121, 625-632.

157 E. Mauri, A. Sacchetti, N. Vicario, L. Peruzzotti-Jametti, F. Rossi and S. Pluchino, Evaluation of RGD functionalization in hybrid hydrogels as 3D neural stem cell culture systems, Biomater. Sci., 2018, 6, 501-510.

158 S. Y. Tong, Z. Wang, P. N. Lim, W. Wang and E. S. Thian, Uniformly-dispersed nanohydroxapatite-reinforced poly(epsilon-caprolactone) composite films for tendon tissue engineering application, Mater. Sci. Eng., C, 2017, 70, 1149-1155.

159 A. J. Heeger, Semiconducting and metallic polymers: the fourth generation of polymeric materials (Nobel lecture), Angew. Chem., Int. Ed., 2001, 40, 2591-2611.

160 T. M. Swager, 50th anniversary perspective: Conducting/ semiconducting conjugated polymers. A personal perspective on the past and the future, Macromolecules, 2017, 50, 4867-4886.

161 A. J. Heeger, N. S. Sariciftci and E. B. Namdas, Semiconducting and metallic polymers, Oxford University Press, Oxford, 2010.

162 W. Changfeng, S. Craig, C. Zachary and M. N. Jason, Conjugated polymer dots for multiphoton fluorescence imaging, J. Am. Chem. Soc., 2007, 129, 12904-12905.

163 P. Johannes and M. Stefan, Nanoparticles of conjugated polymers, Chem. Rev., 2010, 110, 6260-6279.

164 M. Joong Ho, M. D. William, M. Paul and L. F. Hancock, Live-cell-permeable poly(p-phenylene ethynylene), Angew. Chem., Int. Ed., 2010, 46, 8223-8225.

165 L. P. Fernando, P. K. Kandel, Y. Jiangbo, M. N. Jason, A. P. Christine and K. A. Christensen, Mechanism of cellular uptake of highly fluorescent conjugated polymer nanoparticles, Biomacromolecules, 2010, 11, 2675-2682.

166 K. Pu, A. J. Shuhendler and J. Rao, Semiconducting polymer nanoprobe for in vivo imaging of reactive oxygen and nitrogen species, Angew. Chem., Int. Ed., 2013, 52, 10325-10329.

167 X. Guo, M. Baumgarten and K. Müllen, Designing $\pi$-conjugated polymers for organic electronics, Prog. Polym. Sci., 2013, 38, 1832-1908.

168 H. Bohra and M. F. Wang, Direct C-H arylation: a "greener" approach towards facile synthesis of organic semiconducting molecules and polymers, J. Mater. Chem. A, 2017, 5, 11550-11571.

169 M. Wang and F. Wudl, Top-down meets bottom-up: organized donor-acceptor heterojunctions for organic solar cells, J. Mater. Chem., 2012, 22, 24297-24314.

170 A. J. Heeger, 25th anniversary article: bulk heterojunction solar cells: understanding the mechanism of operation, Adv. Mater., 2014, 26, 10-28.

171 L. Y. Lu, T. Y. Zheng, Q. H. Wu, A. M. Schneider, D. L. Zhao and L. P. Yu, Recent advances in bulk heterojunction polymer solar cells, Chem. Rev., 2015, 115, 12666-12731.

172 H. Sirringhaus, 25th anniversary article: organic fieldeffect transistors: the path beyond amorphous silicon, Adv. Mater., 2014, 26, 1319-1335.

173 C. J. Yang, H. Liu, Y. D. Zhang, Z. G. Xu, X. C. Wang, B. Cao and M. F. Wang, Hydrophobic-sheath segregated macromolecular fluorophores: colloidal nanoparticles of polycaprolactone-grafted conjugated polymers with bright far-red/near-infrared emission for biological imaging, Biomacromolecules, 2016, 17, 1673-1683.

174 C. F. Wu and D. T. Chiu, Highly fluorescent semiconducting polymer dots for biology and medicine, Angew. Chem., Int. Ed., 2013, 52, 3086-3109. 
175 K. Li and B. Liu, Polymer-encapsulated organic nanoparticles for fluorescence and photoacoustic imaging, Chem. Soc. Rev., 2014, 43, 6570-6597.

176 H. S. Jung, P. Verwilst, A. Sharma, J. Shin, J. L. Sessler and J. S. Kim, Organic molecule-based photothermal agents: an expanding photothermal therapy universe, Chem. Soc. Rev., 2018, 47, 2280-2297.

177 X. Chen, R. Li, Z. Liu, K. Sun, Z. Sun, D. Chen, G. Xu, P. Xi, C. Wu and Y. Sun, Small photoblinking semiconductor polymer dots for fluorescence nanoscopy, Adv. Mater., 2017, 29, 1604850.

178 Y. Lyu, C. Xie, S. A. Chechetka, E. Miyako and K. Pu, Semiconducting polymer nanobioconjugates for targeted photothermal activation of neurons, J. Am. Chem. Soc., 2016, 138, 9049-9052.

179 A. M. Aravanis, L.-P. Wang, F. Zhang, L. A. Meltzer, M. Z. Mogri, M. B. Schneider and K. Deisseroth, An optical neural interface: in vivo control of rodent motor cortex with integrated fiberoptic and optogenetic technology, J. Neural Eng., 2007, 4, 143-156.

180 D. Ghezzi, M. R. Antognazza, M. Dal Maschio, E. Lanzarini, F. Benfenati and G. Lanzani, A hybrid bioorganic interface for neuronal photoactivation, Nat. Commun., 2011, 2, 166.

181 D. Ghezzi, M. R. Antognazza, R. Maccarone, S. Bellani, E. Lanzarini, N. Martino, M. Mete, G. Pertile, S. Bisti, G. Lanzani and F. Benfenati, A polymer optoelectronic interface restores light sensitivity in blind rat retinas, Nat. Photonics, 2013, 7, 400-406.

182 V. Benfenati, N. Martino, M. R. Antognazza, A. Pistone, S. Toffanin, S. Ferroni, G. Lanzani and M. Muccini, Photostimulation of whole-cell conductance in primary rat neocortical astrocytes mediated by organic semiconducting thin films, Adv. Healthcare Mater., 2014, 3, 392-399.

183 N. Martino, P. Feyen, M. Porro, C. Bossio, E. Zucchetti, D. Ghezzi, F. Benfenati, G. Lanzani and M. R. Antognazza, Photothermal cellular stimulation in functional biopolymer interfaces, Sci. Rep., 2015, 5, 8911.

184 G. Tullii, F. Giona, F. Lodola, S. Bonfadini, C. Bossio, S. Varo, A. Desii, L. Criante, C. Sala, M. Pasini, C. Verpelli, F. Galeotti and M. R. Antognazza, High-aspect-ratio semiconducting polymer pillars for 3D cell cultures, ACS Appl. Mater. Interfaces, 2019, 11, 28125-28137.

185 V. Gautam, M. Bag and K. Narayan, Single-pixel, singlelayer polymer device as a tricolor sensor with signals mimicking natural photoreceptors, J. Am. Chem. Soc., 2011, 133, 17942-17949.

186 V. Gautam, D. Rand, Y. Hanein and K. Narayan, A polymer optoelectronic interface provides visual cues to a blind retina, Adv. Mater., 2014, 26, 1751-1756.

187 M. R. Antognazza, D. Ghezzi, D. Musitelli, M. Garbugli and G. Lanzani, A hybrid solid-liquid polymer photodiode for the bioenvironment, Appl. Phys. Lett., 2009, 94, 243501.

188 G. Simone, D. Di Carlo Rasi, X. de Vries, G. H. Heintges, S. C. Meskers, R. A. Janssen and G. H. Gelinck, Near-infrared tandem organic photodiodes for future application in artificial retinal implants, Adv. Mater., 2018, 30, 1804678.
189 H. Hämmerle, K. Kobuch, K. Kohler, W. Nisch, H. Sachs and M. Stelzle, Biostability of micro-photodiode arrays for subretinal implantation, Biomaterials, 2002, 23, 797-804.

190 H. Xu, Q. Zhu, T. Wu, W. Chen, G. Zhou, J. Li, H. Zhang and N. Zhao, An organic water-gated ambipolar transistor with a bulk heterojunction active layer for stable and tunable photodetection, Appl. Phys. Lett., 2016, 109, 213301.

191 S. Vaquero, C. Bossio, S. Bellani, N. Martino, E. Zucchetti, G. Lanzani and M. R. Antognazza, Conjugated polymers for the optical control of the electrical activity of living cells, J. Mater. Chem. B, 2016, 4, 5272-5283.

192 G. Yu, J. Gao, J. C. Hummelen, F. Wudl and A. Heeger, Polymer photovoltaic cells: enhanced efficiencies via a network of internal donor-acceptor heterojunctions, Science, 1995, 270, 1789-1791.

193 Y. Sun, H. Li, Y. Lin, L. Niu and Q. Wang, Integration of poly (3-hexylthiophene) conductive stripe patterns with 3D tubular structures for tissue engineering applications, RSC Adv., 2016, 6, 72519-72524.

194 E. Zeglio, A. L. Rutz, T. E. Winkler, G. G. Malliaras and A. Herland, Conjugated polymers for assessing and controlling biological functions, Adv. Mater., 2019, 31, e1806712.

195 A. R. Harris and G. G. Wallace, Organic electrodes and communications with excitable cells, Adv. Funct. Mater., 2018, 28, 1700587.

196 R. Ravichandran, S. Sundarrajan, J. R. Venugopal, S. Mukherjee and S. Ramakrishna, Applications of conducting polymers and their issues in biomedical engineering, J. R. Soc., Interface, 2010, 7, 559-579.

197 R. Balint, N. J. Cassidy and S. H. Cartmell, Conductive polymers: Towards a smart biomaterial for tissue engineering, Acta Biomater., 2014, 10, 2341-2353.

198 B. Guo and P. X. Ma, Conducting polymers for tissue engineering, Biomacromolecules, 2018, 19, 1764-1782.

199 A. D. Bendrea, L. Cianga and I. Cianga, Review paper: progress in the field of conducting polymers for tissue engineering applications, J. Biomater. Appl., 2011, 26, 3-84.

200 R. Sridhar, R. Lakshminarayanan, K. Madhaiyan, V. A. Barathi, K. H. C. Lim and S. Ramakrishna, Electrosprayed nanoparticles and electrospun nanofibers based on natural materials: applications in tissue regeneration, drug delivery and pharmaceuticals, Chem. Soc. Rev., 2015, 44, 790-814.

201 Y. Wu, L. Wang, B. Guo, Y. Shao and P. X. Ma, Electroactive biodegradable polyurethane significantly enhanced Schwann cells myelin gene expression and neurotrophin secretion for peripheral nerve tissue engineering, Biomaterials, 2016, 87, 18-31.

202 A. J. Hackett, J. Malmström and J. Travas-Sejdic, Functionalization of conducting polymers for biointerface applications, Prog. Polym. Sci., 2017, 70, 18-33.

203 P. M. George, T. M. Bliss, T. Hua, A. Lee, B. Oh, A. Levinson, S. Mehta, G. Sun and G. K. Steinberg, Electrical preconditioning of stem cells with a conductive polymer scaffold enhances stroke recovery, Biomaterials, 2017, 142, 31-40. 
204 A. Kotwal and C. E. Schmidt, Electrical stimulation alters protein adsorption and nerve cell interactions with electrically conducting biomaterials, Biomaterials, 2001, 22, 1055-1064.

205 C. H. Thompson, M. J. Zoratti, N. B. Langhals and E. K. Purcell, Regenerative electrode interfaces for neural prostheses, Tissue Eng., Part B, 2016, 22, 125-135.

206 C. E. Schmidt, V. R. Shastri, J. P. Vacanti and R. Langer, Stimulation of neurite outgrowth using an electrically conducting polymer, Proc. Natl. Acad. Sci. U. S. A., 1997, 94, 8948-8953.

207 J. Y. Lee, C. A. Bashur, A. S. Goldstein and C. E. Schmidt, Polypyrrole-coated electrospun PLGA nanofibers for neural tissue applications, Biomaterials, 2009, 30, 4325-4335.

208 B. Sun, T. Wu, J. Wang, D. Li, J. Wang, Q. Gao, M. A. Bhutto, H. El-Hamshary, S. S. Al-Deyab and X. Mo, Polypyrrole-coated poly (l-lactic acid-co-e-caprolactone)/silk fibroin nanofibrous membranes promoting neural cell proliferation and differentiation with electrical stimulation, J. Mater. Chem. B, 2016, 4, 6670-6679.

209 P. Zarrintaj, A. M. Urbanska, S. S. Gholizadeh, V. Goodarzi, M. R. Saeb and M. Mozafari, A facile route to the synthesis of anilinic electroactive colloidal hydrogels for neural tissue engineering applications, J. Colloid Interface Sci., 2018, 516, 57-66.

210 S. Wang, C. Sun, S. Guan, W. Li, J. Xu, D. Ge, M. Zhuang, T. Liu and X. Ma, Chitosan/gelatin porous scaffolds assembled with conductive poly (3, 4-ethylenedioxythiophene) nanoparticles for neural tissue engineering, J. Mater. Chem. B, 2017, 5, 4774-4788.

211 Z. Atoufi, P. Zarrintaj, G. H. Motlagh, A. Amiri, Z. Bagher and S. K. Kamrava, A novel bio electro active alginateaniline tetramer/agarose scaffold for tissue engineering: synthesis, characterization, drug release and cell culture study, J. Biomater. Sci., Polym. Ed., 2017, 28, 1617-1638.

212 S. Wang, S. Guan, J. Xu, W. Li, D. Ge, C. Sun, T. Liu and $\mathrm{X}$. Ma, Neural stem cell proliferation and differentiation in the conductive PEDOT-HA/Cs/Gel scaffold for neural tissue engineering, Biomater. Sci., 2017, 5, 2024-2034.

213 L. Ghasemi-Mobarakeh, M. P. Prabhakaran, M. Morshed, M. H. Nasr-Esfahani and S. Ramakrishna, Electrical stimulation of nerve cells using conductive nanofibrous scaffolds for nerve tissue engineering, Tissue Eng., Part A, 2009, 15, 3605-3619.

214 Z. Q. Feng, J. H. Wu, W. R. Cho, M. K. Leach, E. W. Franz, Y. I. Naim, Z. Z. Gu, J. M. Corey and D. C. Martin, Highly aligned poly(3,4-ethylene dioxythiophene) (PEDOT) nanoand microscale fibers and tubes, Polymer, 2013, 54, 702-708.

215 R. Elashnikov, S. Rimpelova, L. Dekanovsky, V. Svorcik and O. Lyutakov, Polypyrrole-coated cellulose nanofibers: influence of orientation, coverage and electrical stimulation on SH-SY5Y behavior, J. Mater. Chem. B, 2019, 7, 6500-6507.

216 N. J. Schaub, C. D. Johnson, B. Cooper and R. J. Gilbert, Electrospun fibers for spinal cord injury research and regeneration, J. Neurotrauma, 2016, 33, 1405-1415.
217 T. H. Qazi, R. Rai and A. R. Boccaccini, Tissue engineering of electrically responsive tissues using polyaniline based polymers: A review, Biomaterials, 2014, 35, 9068-9086.

218 M. R. Abidian, J. M. Corey, D. R. Kipke and D. C. Martin, Conducting-polymer nanotubes improve electrical properties, mechanical adhesion, neural attachment, and neurite outgrowth of neural electrodes, Small, 2010, 6, 421-429.

219 J. Xie, M. R. Macewan, S. M. Willerth, X. Li, D. W. Moran, S. E. Sakiyama-Elbert and Y. Xia, Conductive Core-Sheath Nanofibers and Their Potential Application in Neural Tissue Engineering, Adv. Funct. Mater., 2009, 19, 2312-2318.

220 S. Shafei, J. Foroughi, L. Stevens, C. S. Wong, O. Zabihi and M. Naebe, Electroactive nanostructured scaffold produced by controlled deposition of PPy on electrospun PCL fibres, Res. Chem. Intermed., 2017, 43, 1235-1251.

221 Y.-H. Zhao, C.-M. Niu, J.-Q. Shi, Y.-Y. Wang, Y.-M. Yang and H.-B. Wang, Novel conductive polypyrrole/silk fibroin scaffold for neural tissue repair, Neural Regener. Res., 2018, 13, 1455.

222 J. E. Collazos-Castro, C. Garcia-Rama and A. AlvesSampaio, Glial progenitor cell migration promotes CNS axon growth on functionalized electroconducting microfibers, Acta Biomater., 2016, 35, 42-56.

223 Y. Lu, Y. Li, J. Pan, P. Wei, N. Liu, B. Wu, J. Cheng, C. Lu and L. Wang, Poly(3,4-ethylenedioxythiophene)/poly(styrenesulfonate)-poly(vinyl alcohol)/poly(acrylic acid) interpenetrating polymer networks for improving optrode-neural tissue interface in optogenetics, Biomaterials, 2012, 33, 378-394.

224 L. Yan, B. Zhao, X. Liu, X. Li, C. Zeng, H. Shi, X. Xu, T. Lin, L. Dai and Y. Liu, Aligned nanofibers from polypyrrole/ graphene as electrodes for regeneration of optic nerve via electrical stimulation, ACS Appl. Mater. Interfaces, 2016, 8, 6834-6840.

225 B. Zhu, S. C. Luo, H. C. Zhao, H. A. Lin, J. Sekine, A. Nakao, C. Chen, Y. Yamashita and H. H. Yu, Large enhancement in neurite outgrowth on a cell membrane-mimicking conducting polymer, Nat. Commun., 2014, 5, 4523.

226 P. Zarrintaj, B. Bakhshandeh, I. Rezaeian, B. Heshmatian and M. R. Ganjali, A novel electroactive agarose-aniline pentamer platform as a potential candidate for neural tissue engineering, Sci. Rep., 2017, 7, 1-12.

227 V. Benfenati, S. Toffanin, S. Bonetti, G. Turatti, A. Pistone, M. Chiappalone, A. Sagnella, A. Stefani, G. Generali, G. Ruani, D. Saguatti, R. Zamboni and M. Muccini, A transparent organic transistor structure for bidirectional stimulation and recording of primary neurons, Nat. Mater., 2013, 12, 672-680.

228 C. T. Chen, T. Zhang, Q. Zhang, Z. Q. Feng, C. L. Zhu, Y. L. Yu, K. M. Li, M. Y. Zhao, J. Z. Yang, J. Liu and D. P. Sun, Three-dimensional BC/PEDOT composite nanofibers with high performance for electrode-cell interface, ACS Appl. Mater. Interfaces, 2015, 7, 28244-28253.

229 C. H. Lu, Y. S. Hsiao, C. W. Kuo and P. L. Chen, Electrically tunable organic bioelectronics for spatial and temporal manipulation of neuron-like pheochromocytoma (PC-12) 
cells, Biochim. Biophys. Acta, Gen. Subj., 1830, 2013, 4321-4328.

230 S. Y. Yang, B. N. Kim, A. A. Zakhidov, P. G. Taylor, J. K. Lee, C. K. Ober, M. Lindau and G. G. Malliaras, Detection of transmitter release from single living cells using conducting polymer microelectrodes, Adv. Mater., 2011, 23, 184-188.

231 J. Isaksson, P. Kjall, D. Nilsson, N. D. Robinson, M. Berggren and A. Richter-Dahlfors, Electronic control of $\mathrm{Ca} 2+$ signalling in neuronal cells using an organic electronic ion pump, Nat. Mater., 2007, 6, 673-679.

232 K. C. Larsson, P. Kjall and A. Richter-Dahlfors, Organic bioelectronics for electronic-to-chemical translation in modulation of neuronal signaling and machine-to-brain interfacing, Biochim. Biophys. Acta, Gen. Subj., 1830, 2013, 4334-4344.

233 T. Nyberg, A. Shimada and K. Torimitsu, Ion conducting polymer microelectrodes for interfacing with neural networks, J. Neurosci. Methods, 2007, 160, 16-25.

234 Y. S. Hsiao, Y. H. Liao, H. L. Chen, P. L. Chen and F. C. Chen, Organic photovoltaics and bioelectrodes providing electrical stimulation for PC12 cell differentiation and neurite outgrowth, ACS Appl. Mater. Interfaces, 2016, 8, 9275-9284.

235 S. Y. Kim, K. M. Kim, D. Hoffman-Kim, H. K. Song and G. T. R. Pamore, Quantitative control of neuron adhesion at a neural interface using a conducting polymer composite with low electrical impedance, ACS Appl. Mater. Interfaces, 2011, 3, 16-21.

236 Y. Min, Y. Y. Yang, Y. Poojari, Y. D. Liu, J. C. Wu, D. J. Hansford and A. J. Epstein, Sulfonated polyanilinebased organic electrodes for controlled electrical stimulation of human osteosarcoma cells, Biomacromolecules, 2013, 14, 1727-1731.

237 S. Yang, L. Jang, S. Kim, J. Yang, K. Yang, S. W. Cho and J. Y. Lee, Polypyrrole/alginate hybrid hydrogels: electrically conductive and soft biomaterials for human mesenchymal stem cell culture and potential neural tissue engineering applications, Macromol. Biosci., 2016, 16, 1653-1661.

238 S. M. Richardson-Burns, J. L. Hendricks, B. Foster, L. K. Povlich, D. H. Kim and D. C. Martin, Polymerization of the conducting polymer poly(3,4-ethylenedioxythiophene) (PEDOT) around living neural cells, Biomaterials, 2007, 28, 1539-1552.

239 L. K. Povlich, J. C. Cho, M. K. Leach, J. M. Corey, J. Kim and D. C. Martin, Synthesis, copolymerization and peptidemodification of carboxylic acid-functionalized 3,4ethylenedioxythiophene (EDOTacid) for neural electrode interfaces, Biochim. Biophys. Acta, Gen. Subj., 2013, 1830, 4288-4293.

240 N. Alegret, A. Dominguez-Alfaro and D. Mecerreyes, 3D scaffolds based on conductive polymers for biomedical applications, Biomacromolecules, 2018, 20, 73-89.

241 A. R. Murphy, A. Laslett, C. M. O'Brien and N. R. Cameron, Scaffolds for $3 \mathrm{D}$ in vitro culture of neural lineage cells, Acta Biomater., 2017, 54, 1-20.
242 F. Zamani, M. Amani-Tehran, A. Zaminy and M.-A. Shokrgozar, Conductive 3D structure nanofibrous scaffolds for spinal cord regeneration, Fibers Polym., 2017, 18, 1874-1881.

243 G. D. Mahumane, P. Kumar, L. C. du Toit, Y. E. Choonara and V. Pillay, 3D scaffolds for brain tissue regeneration: architectural challenges, Biomater. Sci., 2018, 6, 2812-2837.

244 L. Zhou, L. Fan, X. Yi, Z. Zhou, C. Liu, R. Fu, C. Dai, Z. Wang, X. Chen, P. Yu, D. Chen, G. Tan, Q. Wang and C. Ning, Soft conducting polymer hydrogels cross-linked and doped by tannic acid for spinal cord injury repair, ACS Nano, 2018, 12, 10957-10967.

245 M. J. Mahoney and K. S. Anseth, Three-dimensional growth and function of neural tissue in degradable polyethylene glycol hydrogels, Biomaterials, 2006, 27, 2265-2274.

246 Z. Q. Shi, H. C. Gao, J. Feng, B. B. Ding, X. D. Cao, S. Kuga, Y. J. Wang, L. N. Zhang and J. Cai, In situ synthesis of robust conductive cellulose/polypyrrole composite aerogels and their potential application in nerve regeneration, Angew. Chem., Int. Ed., 2014, 53, 5380-5384.

247 A. J. Engler, S. Shamik, S. H. Lee and D. E. Discher, Matrix elasticity directs stem cell lineage specification, Cell, 2006, 126, 677.

248 N. D. Leipzig and M. S. Shoichet, The effect of substrate stiffness on adult neural stem cell behavior, Biomaterials, 2009, 30, 6867-6878.

249 D. Huh, G. A. Hamilton and D. E. Ingber, From 3D cell culture to organs-on-chips, Trends Cell Biol., 2011, 21, 745-754.

250 J. Thunberg, T. Kalogeropoulos, V. Kuzmenko, D. Hagg, S. Johannesson, G. Westman and P. Gatenholm, In situ synthesis of conductive polypyrrole on electrospun cellulose nanofibers: scaffold for neural tissue engineering, Cellulose, 2015, 22, 1459-1467.

251 B. Xu, T. Bai, A. Sinclair, W. Wang, Q. Wu, F. Gao, H. Z. Jia, S. Y. Jiang and W. G. Liu, Directed neural stem cell differentiation on polyaniline-coated high strength hydrogels, Mater. Today Chem., 2016, 1, 15-22.

252 Y. S. Kim, K. Cho, H. J. Lee, S. Chang, H. Lee, J. H. Kim and W. G. Koh, Highly conductive and hydrated PEG-based hydrogels for the potential application of a tissue engineering scaffold, React. Funct. Polym., 2016, 109, 15-22.

253 P. Zou, Y. Zhao, A. D. Douglass, D. R. Hochbaum, D. Brinks, C. A. Werley, D. J. Harrison, R. E. Campbell and A. E. Cohen, Bright and fast multicoloured voltage reporters via electrochromic FRET, Nat. Commun., 2014, 5, 4625 .

254 J. M. Kralj, A. D. Douglass, D. R. Hochbaum, D. Maclaurin and A. E. Cohen, Optical recording of action potentials in mammalian neurons using a microbial rhodopsin, Nat. Methods, 2011, 9, 90-95.

255 D. R. Hochbaum, Y. Zhao, S. L. Farhi, N. Klapoetke, C. A. Werley, V. Kapoor, P. Zou, J. M. Kralj, D. Maclaurin, N. Smedemark-Margulies, J. L. Saulnier, G. L. Boulting, C. Straub, Y. K. Cho, M. Melkonian, G. K. Wong, D. J. Harrison, V. N. Murthy, B. L. Sabatini, E. S. Boyden, 
R. E. Campbell and A. E. Cohen, All-optical electrophysiology in mammalian neurons using engineered microbial rhodopsins, Nat. Methods, 2014, 11, 825-833.

256 T. W. Chen, T. J. Wardill, Y. Sun, S. R. Pulver, S. L. Renninger, A. Baohan, E. R. Schreiter, R. A. Kerr, M. B. Orger, V. Jayaraman, L. L. Looger, K. Svoboda and D. S. Kim, Ultrasensitive fluorescent proteins for imaging neuronal activity, Nature, 2013, 499, 295-300.

257 T. J. O’Shaughnessy, J. L. Liu and W. Ma, Passaged neural stem cell-derived neuronal networks for a portable biosensor, Biosens. Bioelectron., 2009, 24, 2365-2370.

258 M. Heim, B. Yvert and A. Kuhn, Nanostructuration strategies to enhance microelectrode array (MEA) performance for neuronal recording and stimulation, J. Physiol., 2012, 106, 137-145.

259 M. E. J. Obien, K. Deligkaris, T. Bullmann, D. J. Bakkum and U. Frey, Revealing neuronal function through microelectrode array recordings, Front. Neurosci., 2015, 8, 423.

260 S. R. Braam, L. Tertoolen, A. Van de Stolpe, T. Meyer, R. Passier and C. L. Mummery, Prediction of drug-induced cardiotoxicity using human embryonic stem cell-derived cardiomyocytes, Stem Cell Res., 2010, 4, 107-116.

261 M. Dipalo, G. C. Messina, H. Amin, R. La Rocca, V. Shalabaeva, A. Simi, A. Maccione, P. Zilio, L. Berdondini and F. De Angelis, 3D plasmonic nanoantennas integrated with MEA biosensors, Nanoscale, 2015, 7, 3703-3711.

262 T. Cramer, A. Campana, F. Leonardi, S. Casalini, A. Kyndiah, M. Murgia and F. Biscarini, Water-gated organic field effect transistors - opportunities for biochemical sensing and extracellular signal transduction, J. Mater. Chem. B, 2013, 1, 3728-3741.

263 C. S. Lee, S. K. Kim and M. Kim, Ion-sensitive field-effect transistor for biological sensing, Sensors, 2009, 9, 7111-7131.

264 M. J. Schöning, "Playing around" with field-effect sensors on the basis of EIS structures, LAPS and ISFETs, Sensors, 2005, 5, 126-138.

265 K. S. Chang, C. J. Sun, P. L. Chiang, A. C. Chou, M. C. Lin, C. Liang, H. H. Hung, Y. H. Yeh, C. D. Chen, C. Y. Pan and Y. T. Chen, Monitoring extracellular $\mathrm{K}+$ flux with a valinomycin-coated silicon nanowire field-effect transistor, Biosens. Bioelectron., 2012, 31, 137-143.

266 P. B. Kruskal, Z. Jiang, T. Gao and C. M. Lieber, Beyond the patch clamp: nanotechnologies for intracellular recording, Neuron, 2015, 86, 21-24.

267 C. Zhang, P. Chen and W. Hu, Organic field-effect transistorbased gas sensors, Chem. Soc. Rev., 2015, 44, 2087-2107.

268 T. Cramer, B. Chelli, M. Murgia, M. Barbalinardo, E. Bystrenova, D. M. de Leeuw and F. Biscarini, Organic ultra-thin film transistors with a liquid gate for extracellular stimulation and recording of electric activity of stem cell-derived neuronal networks, Phys. Chem. Chem. Phys., 2013, 15, 3897-3905.

269 D. Khodagholy, T. Doublet, P. Quilichini, M. Gurfinkel, P. Leleux, A. Ghestem, E. Ismailova, T. Hervé, S. Sanaur and C. Bernard, In vivo recordings of brain activity using organic transistors, Nat. Commun., 2013, 4, 1-7.
270 D. Khodagholy, J. N. Gelinas, T. Thesen, W. Doyle, O. Devinsky, G. G. Malliaras and G. Buzsáki, NeuroGrid: recording action potentials from the surface of the brain, Nat. Neurosci., 2015, 18, 310-315.

271 A. C. Patil and N. V. Thakor, Implantable neurotechnologies: a review of micro-and nanoelectrodes for neural recording, Med. Biol. Eng. Comput., 2016, 54, 23-44.

272 G. P. Kittlesen, H. S. White and M. S. Wrighton, Chemical derivatization of microelectrode arrays by oxidation of pyrrole and N-methylpyrrole: fabrication of molecule-based electronic devices, J. Am. Chem. Soc., 1984, 106, 7389-7396.

273 Q. Qing, S. K. Pal, B. Tian, X. Duan, B. P. Timko, T. CohenKarni, V. N. Murthy and C. M. Lieber, Nanowire transistor arrays for mapping neural circuits in acute brain slices, Proc. Natl. Acad. Sci. U. S. A., 2010, 107, 1882-1887.

274 B. P. Timko, T. Cohen-Karni, G. Yu, Q. Qing, B. Tian and C. M. Lieber, Electrical recording from hearts with flexible nanowire device arrays, Nano Lett., 2009, 9, 914-918.

275 G. Buzsáki, C. A. Anastassiou and C. Koch, The origin of extracellular fields and currents-EEG, ECoG, LFP and spikes, Nat. Rev. Neurosci., 2012, 13, 407-420.

276 J. A. Blanco, M. Stead, A. Krieger, J. Viventi, W. R. Marsh, K. H. Lee, G. A. Worrell and B. Litt, Unsupervised classification of high-frequency oscillations in human neocortical epilepsy and control patients, J. Neurophysiol., 2010, 104, 2900-2912.

277 M. Stead, M. Bower, B. H. Brinkmann, K. Lee, W. R. Marsh, F. B. Meyer, B. Litt, J. Van Gompel and G. A. Worrell, Microseizures and the spatiotemporal scales of human partial epilepsy, Brain, 2010, 133, 2789-2797.

278 Y. Goda and M. A. Colicos, Photoconductive stimulation of neurons cultured on silicon wafers, Nat. Protoc., 2006, 1, 461-467.

279 B. Valentina, T. Stefano, B. Simone, T. Guido, P. Assunta, C. Michela, S. Anna, S. Andrea, G. Gianluca and R. J. N. M. Giampiero, A transparent organic transistor structure for bidirectional stimulation and recording of primary neurons, Nat. Mater., 2013, 12, 672-680.

280 E. Mosconi, P. Salvatori, M. I. Saba, A. Mattoni, S. Bellani, F. Bruni, B. Santiago Gonzalez, M. R. Antognazza, S. Brovelli and G. Lanzani, Surface polarization drives photoinduced charge separation at the P3HT/water interface, ACS Energy Lett., 2016, 1, 454-463.

281 J. X. Li, B. E.-F. de Ávila, W. Gao, L. F. Zhang and J. Wang, Micro/nanorobots for biomedicine: Delivery, surgery, sensing, and detoxification, Sci. Robot., 2017, 2, 6431.

282 C. Xin, L. Yang, J. W. Li, Y. Hu, D. D. Qian, S. Y. Fan, K. Hu, Z. Cai, H. Wu and D. W. Wang, Conical hollow microhelices with superior swimming capabilities for targeted cargo delivery, Adv. Mater., 2019, 31, 1808226.

283 X. K. Lin, Z. G. Wu, Y. J. Wu, M. J. Xuan and Q. He, Selfpropelled micro-/nanomotors based on controlled assembled architectures, Adv. Mater., 2016, 28, 1060-1072.

284 M. A. Nicolelis, Brain-machine interfaces to restore motor function and probe neural circuits, Nat. Rev. Neurosci., 2003, 4, 417-422. 